\author{
KA Al-Anazi ${ }^{1 \star}$ and AM Al-Jasser ${ }^{2}$ \\ ${ }^{1}$ Department of Adult Hematology and \\ Hematopoietic Stem Cell Transplantation, Oncology \\ Center, King Fahad Specialist Hospital, Saudi \\ Arabia \\ ${ }^{2}$ Riyadh Regional Laboratory, Ministry of Health, \\ Riyadh 11575, Saudi Arabia \\ Dates: Received: 21 April, 2016; Accepted: 19 May, \\ 2016; Published: 26 May, 2016 \\ *Corresponding author: Dr Khalid Ahmed Al- \\ Anazi, Consultant and Chairman, Department of \\ Adult Hematology and Hematopoietic Stem Cell \\ Transplantation, Oncology Center, King Fahad \\ Specialist Hospital, P.O. Box: 25215, Dammam \\ 31444, Saudi Arabia, Tel: 966-03-8431111; Fax: 966- \\ 03-8427420; E-mail: kaa_alanazi@yahoo.com \\ www.peertechz.com
}

\author{
Review Article
}

\section{Brucellosis in Immunocompromised}

\section{Hosts}

\section{Abbreviations}

HSCT: Hematopoietic Stem Cell Transplantation; SOT: Solid Organ Transplantation; RT-PCR: Real Time-Polymerase Chain Reaction; B.: Brucella; LPS: Lipopolysaccharide; IL: Interleukin; TNF: Tumor Necrosis Factor; HIV: Human Immunodeficiency Virus; CMV: Cytomegalovirus; H1N1: Swine Flu Virus; ESR: Erythrocyte Sedimentation Rate; CRP: C-Reactive Protein; ESRD: End-Stage Renal Disease; DIC: Disseminated Intravascular Coagulation; MAHA: Microangiopathic Hemolytic Anemia; CNS: Central Nervous System; FUO: Fever Of Unknown Origin; EO: Epidedymo-Orchitis; ELISA: Enzyme-Linked Immunosorbent Assay; RA: Rheumatoid Arthritis; MLVA: Multi-Locus Variable Number Tandem Repeats Assay; FDG: Fluoro-18-fluoro-2-Deoxy-D-Glucose; PET: Positron Emission Tomography; CAT: Computerized Axial Tomography; BE: Brucella Endocarditis; MRI: Magnetic Resonance Imaging

\section{Introduction}

Recently, brucellosis has been increasingly recognized in patients with comorbid medical conditions and in immunocompromised individuals [1]. The infective dose is relatively low as 10 to 100 organisms are sufficient to cause the disease [2]. The duration of the incubation period ranges between one week and several months. During this period of time, the clinical features are non-specific $[1,3]$. Brucellosis may present as an acute febrile illness or as a chronic medical condition. Additionally, it can cause a localized infection or a generalized disease with systemic manifestations [1,3]. The course of the disease varies considerably from totally asymptomatic to a severe illness that is potentially fatal. Complications, chronic infections and relapses are prone to occur particularly in patients with low immunity $[1,3]$.

Human brucellosis has protean clinical manifestations and the occasionally misleading clinical picture may contribute to underdiagnosis of the disease. Consequently, complications may evolve and treatment may be delayed [4]. Therefore, sustaining a high index of suspicion is important as early diagnosis and prompt therapy improve the outcome and prevent complications $[1,3,4]$.

This review on Brucella infections in immunocompromised individuals, will be an update on the following aspects of brucellosis: (1) epidemiology, pathogenesis, microbiology, clinical manifestations and complications, (2) Brucella infections in various categories of immunocompromised individuals, and (3) diagnostic techniques, available therapies, prevention and control of the infection. However, particular attention will be given to brucellosis in recipients of stem cell and solid organ transplantation.

\section{Incidence and epidemiology}

Brucellosis is an infectious disease of animals (zoonosis) that is transmittable to humans by wild and domestic animals [5]. Several Brucella species have been identified, 6 of which are human pathogens [5-8]. The incidence of brucellosis varies considerably from time to time and from one country to another $[9,10]$. Several studies have shown that the annual incidence of brucellosis per million of population is as follows: 0.09 in Canada; 0.3-0.9 in the United States of America, the United Kingdom, Sweden and the Netherlands; 211495 in Turkey; 606 in Mongolia; 362-880 in Kyrgyzstan; 214-1376 in Saudi Arabia; 239-1416 in Iran and 1603 in Syria [9,10].

The infection is global in distribution, but it is endemic in the Mediterranean and Middle East regions, Indian subcontinent, Mexico and parts of Central and South America [11-14]. In the era of globalization and international tourism, brucellosis has become a common imported disease in the developed world $[9,15]$. It is estimated that $60 \%$ of emerging human pathogens are zoonotic [16]. Brucellosis is the commonest zoonotic infection worldwide as it has been reported in 56 countries and as more than 500,000 new cases of brucellosis are reported annually $[8,9,12]$. Additionally brucellosis is a notifiable disease in most countries [17]. 
The epidemiology of human brucellosis has changed over the last 25 years $[9,10]$. Unfortunately, in many Brucella-endemic countries, the health systems are weak and official data are likely to underestimate the true burden of the disease [10]. Also, local traditional medicines including herbal medications are commonly used to treat Brucella infections in certain countries such as Tanzania [14]. The resurgence and the recent increase in the incidence of brucellosis can be attributed to: (1) socioeconomic changes, (2) wars and political turbulence in some countries that are endemic for the disease, (3) inadequate infection control programs in some countries, (4) international tourism due to the recent ease of human travel, (5) uncontrolled animal transportation across open borders, (6) the complexity of the disease which has different cycles of expansion and regression, and (7) the recent increase in the number of immunocompromised individuals and their longer survival which is mainly attributed to the recent improvements in medical care [9,10,18-21].

\section{Risk factors and transmission of brucellosis}

The risk factors for Brucella infection include: consumption of raw milk and unpasteurized dairy products, direct contact with animals and their products, male sex and age between 40 and 49 years $[2,7,9,10,17,22,26]$. Brucellosis is an occupational disease that poses risk to shepherds, abattoir workers, veterinarians and personnel working in diary-industry and microbiology laboratories $[2,7,26]$. Brucellosis is commonly transmitted by: (1) consumption of unpasteurized or contaminated animal dairy products, (2) direct contact with infected animal parts and (3) inhalation of infected aerosolized particles. Less common means of transmission of the disease include: (1) person to person transmission, (2) blood transfusion, (3) transfusion of harvested bone marrow in recipients of hematopoietic stem cell transplantation (HSCT), and (4) sexual transmission, as in the few reported cases of sexually transmitted brucellosis in humans, the organisms were either cultured from semen or their presence in serum was demonstrated by polymerase chain reaction (PCR) [2,7,23-25,27,32].

\section{Microbiological aspects}

The organism is a Gram negative, non-spore-forming, coccobacillus [7]. It is aerobic, partially acid fast and has short rods [11]. It is localized predominantly to organs with numerous macrophages such as lungs, liver, spleen, bone marrow and synovium [7]. Several species have been recognized and the following 6 species are pathogenic to humans: B. melitensis, B. abortus, B. suis, B. canis, $B$. ceti and B. pinnipedialis [5-8]. The organism is shed in milk, fetal membrane, semen and uterine discharges. Reservoirs of Brucella infection include goats, sheep, camels, cattle, dogs, pigs and deers [2].

$B$. canis infections are rarely reported in humans. Between 1999 and 2010, only 11 cases of B. canis infection in humans had been reported in Japan [33]. In a febrile person who has signs and symptoms of unknown cause and history of contact with animals, B. canis infection should be considered and appropriate action to prevent spread of infection should be taken [33].

\section{Seroprevalence and blood transfusion-related brucellosis}

Several studies on seroprevalence of brucellosis in high risk human populations in countries which are endemic for the disease have shown that the seroprevalence figures are as follows: $8.8 \%$ in Kyrgyzstan; 2.2-21.6\% in Bangladesh; 6.9\% in Pakistan; $24.1 \%$ in Nigeria; $27.3 \%$ in Mongolia and 15\% in Saudi Arabia [34-39].

Blood transfusion as a means of transmission of brucellosis in recipients of blood product transfusions had been reported since the year 1950. Screening of blood donors for brucellosis has revealed that Brucella antibodies are present in the serum samples of $0.06 \%$ to $3.2 \%$ of blood donors $[27,28,32]$. Although brucellosis is a bloodborne pathogen, there have been either rare or no reports of blood transfusion-transmitted brucellosis in certain countries that are endemic for brucellosis [40]. However, in a study performed in China in which 3896 plasma samples had been collected, 15 blood donations, that is, $1: 300$ cases were found to be positive by nucleic acid testing and they were confirmed by DNA sequencing [41]. The data indicate that a probable high rate of Brucella bacteremia suggesting a potential risk of transfusion transmitted brucellosis. Therefore, screening of donated blood for Brucella infection should be considered in highly endemic geographic locations [41].

Although the prevalence is not high, brucellosis could be a risk for blood transfusion and blood donors coming from rural areas in endemic geographic locations should be screened for brucellosis [42]. Also, they should be asked about consumption of unpasteurized milk and dairy products as well as contact with infected animals [42]. In a Turkish study that included 632 volunteers for blood donation, 4 donors had positive serology for brucellosis and Brucella species was detected by right time (RT)-PCR in 2 donors [42]. However, the clinical manifestations of bacterial sepsis due to Brucella infection related to blood transfusion may include: fever, rigors, tachycardia, hypotension, nausea, vomiting, dyspnea and back pain [40].

\section{Pathogenesis of brucellosis}

The pathogenicity of human brucellosis is attributed to factors such as lipopolysaccharide (LPS), adenine and guanine monophosphate, vitamin B, $24 \mathrm{KDa}$ protein and urease enzyme [11]. In the past decade, the mechanisms of Brucella pathogenesis and host protective immunity against Brucella infections have been extensively investigated using cutting edge systems biology and bioinformatics approaches [43]. The persistence of bacterial colonization in the cells of the reticuloendothelial system is an important feature of brucellosis [44]. The ability of some Brucellae to survive the reactive oxygen intermediate and the nitric oxide killing in the host phagocytes results in the chronicity of brucellosis [45].

Production of interferon- $\gamma($ IFN- $\gamma$ ) results from the ability of Brucella components, including lipid A, to interact with Tolllike receptors for the production of interleukin (IL)-12 and tumor necrosis factor (TNF)- $\alpha$, although the regulatory cytokine IL-10 is also produced and decreases control of the infection [45].

IFN- $\gamma$ is a crucial component of immunity that limits intracellular replication of various Brucella species thus maintaining a chronic infective state in the host [45].

Three mechanisms are involved in the immune response to brucellosis: (1) interferon- $\gamma$ activates the bacterial function in macrophages to hamper the intracellular survival of Brucella 
species, (2) cytotoxicity of CD8 $8_{+}$and $\gamma \overline{\text { T} T}$ cells destroy the infected macrophages, and (3) $\mathrm{Th}_{1}$-type antibodies opsonize the pathogen to facilitate phagocytosis [46]. The granulomatous response is a characteristic feature of $B$. abortus infection. In B. melitensis, the granulomata are very small while $B$. suis infection is associated with chronic abscess formation [46]. LPS has a role in cell entry and immune evasion of the infected cell and is essential for intracellular survival. Brucella species invade and persist in the host via inhibition of programed cell death and replication of the bacterium takes place in the endoplasmic reticulum [46]. The human host response is both humoral and T-cell mediated, although cell mediated immunity appears to be the principal mechanism of recovery. Antibodies are important for diagnostic purposes but appear to play a minor role in the immune response to infection [46]. It is well established that infection with some intracellular bacteria may have an indirect effect on the immune system, thus ultimately leading to immunosuppression. Among the leading bacterial causes of immunosuppression are $B$. melitensis and Mycobacterium tuberculosis [47]. Survival of Brucella species within monocytes is the single most important aspect of pathogenesis contributing to persistence of the bacteria in host tissues [48].

Recently, molecular studies have highlighted the pathogenesis of Brucella species and this will accelerate the development of new diagnostic techniques that are useful in developing countries where brucellosis, despite being common, is often neglected [49]. Genetic studies have shown that $B$. abortus and B. melitensis share the same lineage and differ from $B$. suis which has undergone few genetic mutations and has diverged from the most recent ancestor of all Brucellae [49]. Increased serum levels of IL-6, IL-8 and IL-12 have been reported in patients with brucellosis, while IL-8-251AA and rs3212227AA genotypes have been found to increase the genetic susceptibility to acquire Brucella infections [50,51]. Additionally, the neutrophil/lymphocyte ratio in the blood has been found to be significantly associated with Brucella infection in humans [52].

\section{Virulence of Brucella species}

Although Brucella does not bear classic virulence factors, the organism tends to invade and persist in human hosts [6]. Virulence of Brucella species relies on the ability of the organism to survive and replicate in the in the host cells $[43,53]$. Although these virulence factors are critical for replication of the organism inside host cells, they may not directly mediate the clinical manifestations of brucellosis [53]. Several Brucella virulence factors have been identified and they include: (1) LPS, (2) type 4 secretion systems (T4SSs), and (3) the BvrR/BvrS two-component system [43,54,55].

Secretion of proteins across membranes is of vital importance in bacterial virulence [54]. The T4SSs are membrane-associated transporter complexes that are used by various bacterial species to deliver substrate molecules to a wide range of target cells and they contribute to the following important processes: (1) exchange of genetic material, (2) bacterial colonization and biofilm formation, and (3) injection of virulence factors into the host cytoplasm [54]. Several lines of evidence indicate that the role of virulence in Brucella species is important [54]. The T4SS, which is encoded by the virB locus, is located on chromosome 2. The Brucella species
T4SS, encoded by virB1 and virB12 locus, is required for intracellular replication and persistent infection in vivo [55]. During infection in both experimental animals and natural hosts of Brucella species, virB12 is expressed, so it may be a useful serodiagnostic marker of brucellosis [55]. Additionally, antibodies to B. abortus virB12 have been identified in mice, goat and cattle. Therefore, detection of humoral responses to virB12-specific immune responses can be used in the diagnostic algorithm of human brucellosis [55]. $B$. microti exhibits a high pathogenic potential in experimental murine infections [56]. Lethality of B. microti in murine infections primarily requires a functional virB12 operon [56]. The T4SS, encoded by virB operon, is the most-studied and best-characterized virulence factor of Brucella species [56].

During the past decade, systems biology and bioinformatic approaches have been widely used to: (1) study the mechanisms of Brucella pathogenesis and host protective immunity against Brucella infections, and (2) support vaccine design [43]. Based on more than 30 sequenced Brucella genomes, comparative genomics is able to identify gene variations among Brucella strains that help to explain host specificity and differences in virulence among Brucella species [43]. More than 180 virulence factors and their gene interaction networks have been identified using advanced literature mining methods [43].

\section{Clinical manifestations of brucellosis}

The incubation period of brucellosis is usually 1-4 weeks, but may be as long as several months [1]. Generally, B. melitensis causes more severe infections than B. abortus, B. suis causes human infections that are as severe as those caused by $B$. melitensis, and $B$. canis which is infrequently encountered in humans causes mild disease [1].

High grade, irregular fever which has insidious onset and that lasts for days to weeks is the commonest clinical feature. However, brucellosis may present as fever of unknown origin (FUO) and the infection may occasionally be atypical $[1,11]$. The other clinical features of brucellosis include: night sweats, chills and rigors, anorexia, malaise, weakness, weight loss, headache, arthralgia, myalgia, low backache, dizziness, depressed mood, dyspepsia, nausea, vomiting, abdominal pain, cough, dyspnea, epistaxis and hemoptesis, burning micturition, testicular pain, swollen and tender joints, tenderness over the lumbosacral spine, splenomegaly, hepatomegaly, external lymphadenopathy, jaundice, mouth ulcerations, scrotal swelling in addition to various cutaneous eruptions [1-5,9-11,22,57,61]. In a study performed in Saudi Arabia that included 73 episodes of brucellosis in 55 patients, $44 \%$ of the patients had rheumatic manifestations such as arthritis and spondylitis [62]. Brucellosis can have several presentations and the disease has several stages: acute, sub-acute, chronic, relapsing, active and non-active. Therefore, discriminatory, diagnostic as well as prognostic markers, particularly for monitoring disease activity are ongoing. Also, despite the progress that has been achieved, several challenges remain [63].

\section{Cardiovascular complications of brucellosis}

Cardiovascular complications occur in approximately 1\%-2\% of patients with brucellosis [64-67]. Cardiac complications of Brucella infection include: endocarditis, myocarditis, pericarditis, pericardial 
effusions and heart failure. Pericarditis, myocarditis and pericardial effusions can be encountered in the absence of endocarditis $[65,66,68,69]$. Also, isolated cases of Brucella myopericarditis have been reported [67].

Brucella endocarditis (BE) occurs in less than $2 \%$ of patients with brucellosis, but it is serious and may be life-threatening [68,70-72]. $\mathrm{BE}$ can affect native or prosthetic heart valves and the aortic valve is involved in $75 \%$ of cases. Underling pathologies, such as rheumatic heart disease or degenerative heart valves, are usually present [68,70-72]. The clinical manifestations of BE include: fever, dyspnea, fatigue, weight loss, a new heart murmur and valve dysfunction or regurgitation in addition to external palpable lymphadenopathy and hepatosplenomegaly [68,70-72]. BE can be complicated by: annulus abscess, pericarditis, congestive cardiac failure, septic emboli and death $[68,70,71] . \mathrm{BE}$ is the main cause of death in patients with brucellosis and mortality rate due to BE is about: $20 \%-30 \%[68,72]$. Blood cultures are usually positive in $17 \%-85 \%$ of patients with $\mathrm{BE}$ [70,71]. Echocardiographic findings include: valve dysfunction, vegetations, ulcerations and abscess formation [70,71]. BE can be treated by: (1) surgical intervention in the form of valve replacement, and (2) antimicrobial therapy which should be administered for 3 weeks before surgery in order to ensure hemodynamic stability and achievement of sterilization before surgical therapy [68,70-72]. Postoperatively, $\mathrm{BE}$ patients require prolonged courses of antimicrobial therapy. The following antibiotics have been utilized in the treatment of BE: doxycycline or tetracycline, rifampicin, streptomycin and ceftriaxone [68,70-72]. In patients with $\mathrm{BE}$, who are hemodynamically stable and having no complications, combinations of antimicrobials may be sufficient and may rule out the need for surgical intervention [72]. A high degree of suspicion is required in areas that are endemic for brucellosis [68,71].

Brucella pericarditis is very rare [66]. It may be almost asymptomatic or may cause cardiac tamponade [67]. The following lines of management are usually undertaken: pericardiocentesis, antibiotics and symptomatic treatment in the form of analgesics and anti-inflammatory drugs [66]. Pericardiocentesis should only be performed in patients with cardiac tamponade [66,67]. Although Brucella pericarditis is usually associated with low morbidity and mortality, it should always be kept in mind in patients with acute or chronic pericarditis particularly in individuals living in areas that are endemic for brucellosis [66].

Brucella myocarditis is also a very rare complication of brucellosis and only few cases have been reported in literature $[64,69,73]$. It may be complicated by heart failure [69]. Severe myocarditis complicating acute brucellosis may be fatal [64]. Brucella myocarditis may occur in isolation or as part of disseminated Brucella infection [64]. Patients with Brucella myocarditis usually experience prolonged pyrexia, high C-reactive protein and delayed enhancement of cardiac ventricular walls on magnetic resonance imaging (MRI) [73]. Combination of doxycycline and rifampicin for 3 months may be curative [73]. However, early diagnosis and prompt initiation of appropriate antimicrobials are essential to prevent complications of Brucella myocarditis [64].

\section{Neurobrucellosis}

Both central and peripheral nervous systems can be affected by brucellosis [74]. Central nervous system (CNS) involvement, although uncommon, is a serious complication of brucellosis. It has been reported in $1.7 \%-11 \%$ of patients with brucellosis [7478]. Neurobrucellosis presents in a heterogeneous manner and the clinical manifestations and complications may include: fever, headache, nausea, vomiting, sweating, weakness, weight loss, back pain, neck stiffness, hearing loss, mental confusion, coma, convulsions, depression, dementia, papilledema, optic neuropathy, stroke, paraplegia, motor deficits, polyneuropathy, radiculopathy, cranial nerve palsies, pseudotumor cerebri, hydrocephalus, subarachnoidal hemorrhage, subdural hematoma, sagittal sinus thrombosis, intracranial vasculitis, spinal arachnoiditis, brain or paraspinal abscess, meningitis, encephalitis, transverse myelitis, hepatosplenomegaly and death [74-78].

Blood investigations usually show: leucopenia or leukocytosis, elevated erythrocyte sedimentation rate (ESR) and C-reactive protein (CRP) [77]. Cerebrospinal fluid (CSF) analysis usually shows: lymphocytic pleocytosis, high protein, low glucose, positive cultures and positive CSF Brucella serology [74,75,77,78]. Computerized axial tomography etc. (CAT) scans and MRI of brain and spinal cord may show: space occupying lesions such as granulomas or abscess formation and white matter lesions with demyelination [74,77,78]. Neurobrucellosis should be differentiated from: neurosyphilis, neurotuberculosis and other causes of purulent meningitis [75].

For Brucella meningitis, initially parenteral third generation cephalosporin such as ceftriaxone should be given, followed by various combinations of antimicrobials including: doxycycline, rifampicin, streptomycin or trimethoprim-sulfamethoxazole (TMP/ SMZ) [74,75,77]. The duration of antimicrobial therapy varies between 2 and 17 months with a median duration of 5 to 6 months [75-77]. However, treatment should be individualized according to the complications encountered [75]. Neurobrucellosis is rarely fatal provided the diagnosis is made early and appropriate therapy is administered promptly $[74,76]$. With appropriate treatment, mortality due to neurobrucellosis is approximately $0.5 \%$, while untreated neurobrucellosis is associated with high morbidity and mortality [74-76] Physicians working in geographic locations that are endemic for brucellosis should maintain a high index of suspicion and should consider neurobrucellosis in patients presenting with unexplained neurological manifestations or psychiatric symptoms $[74,77,78]$.

\section{Other serious complications of Brucella infection}

Rare but potentially life-threatening complications of brucellosis include: (1) disseminated infection with nodules and abscesses in the liver, spleen, gall bladder, lung, pleura and spine, (2) pancytopenia combined with endocarditis or meningitis, and (3) Brucella bacteremia that may cause septic shock [79-82]. Complicated infections are more likely to occur in immunocompromised hosts and require prompt diagnosis and early institution of appropriate therapy that includes surgical drainage, antimicrobial chemotherapy, artificial ventilation and transfusion of blood products [79-82].

\section{Relapse of brucellosis:}

Relapses occur in up to $29 \%$ of patients with brucellosis and 
they usually occur within 12 months of discontinuation of the antimicrobial therapy $[1,3,5,58,62]$. The risk factors for relapse include: male sex, old age, lymphopenia, deficient immunologic response such as in patients having human immunodeficiency virus (HIV) infection, presence of an aggressive disease or a chronic infection, positive blood cultures during initial infection, and an inadequately treated infection $[1,3,5,83-86]$. The laboratory findings in relapsing brucellosis are positive blood cultures in addition to elevation of the erythrocyte sedimentation rate (ESR) as well as CRP $[3,15,84]$. Most relapses can be successfully treated with longer courses of the standard therapeutic regimens and surgical intervention in case of localized foci of infection $[1,3,5,58]$.

\section{Chronic brucellosis:}

Chronic brucellosis traditionally refers to the persistence of clinical manifestations for at least one year after establishment of the diagnosis of brucellosis [1,3]. It is characterized by: (1) localized infection such as spondylitis or osteomyelitis, (2) relapse in patients with an objective evidence of infection and (3) manifestations such as chronic fatigue syndrome and psychoneurosis $[1,3,5]$. The diagnosis of chronic brucellosis should be established on clinical grounds and history of the illness [1,87-92].

\section{Reactivation of old Brucella infections}

Reactivations of old Brucella infections have been reported 28 and even 70 years after the primary infection $[93,94]$. The risk factors for reactivation of old brucellosis include: old age, malignancy such as lymphoma, chronic medical illness such as hepatitis $\mathrm{C}$, cytotoxic chemotherapy and immunosuppressive agents such as interferon [93-95].

\section{Recovery of Brucella species from old human remains}

Ancient skeletal remains can harbor unique information about past civilizations at both morphological and molecular levels. The occurrence of brucellosis in archaeologically recovered human bones, belonging to 2 young patients who lived in Albania between the 10th and 13th centuries, has been confirmed using DNA sequencing technology [96]. Also, 6 old cases of brucellosis with skeletal involvement belonging to the period between the 5th and 12th centuries have been recovered from Western Europe Mediterranean countries using molecular techniques such as PCR.

The recovery DNA sequence of a certain pathogen from human remains provides an opportunity to identify and characterize the causes of individual and epidemic infections [97]. Shotgun metagenomics provide an approach to recover pathogen genomes from historical material [98]. The DNA, which had been extracted from medieval human remains using shotgun metagenomics, was sequenced and a draft genome sequence of a 700-year-old B. melitensis strain was obtained [98]. Bioinformatic approaches showed that the historical strain is most closely related to the recent $B$. melitensis strains isolated from Italy [98].

\section{Brucellosis in immunocompromised patients}

In immunocompromised individuals: (1) the clinical manifestations of brucellosis may be similar to those in immunocompetent individuals, (2) the diagnosis may be delayed due to overlapping between the clinical features of brucellosis and those of the underlying disease, (3) more complications are prone to develop and (4) treatment of brucellosis may be delayed and may become difficult due to the interactions between anti-Brucella medications and cytotoxic chemotherapeutic agents as well as immunosuppressive drugs [99-112].

\section{Brucellosis in solid organ transplantation (SOT)}

Currently, SOT that includes transplantation of kidney, lung, heart, liver, pancreas and small bowel is the treatment of choice for many end-stage diseases $[104,113]$. Since the first successful kidney transplantation in 1954, SOT has increased worldwide as currently more than 70,000 SOTs are performed annually [113,114].

As a consequence of improved immunosuppressive therapy and graft survival, infection and malignancy have become the main barriers to disease free survival after SOT [114]. Infectious causes remain a major complication in SOT recipients as they are associated with significant morbidity and mortality [104]. However, the risk of transmission of an infectious agent from the organs obtained from deceased or cadaveric donors is less than 1\% [104]. As a result of growing population of immunocompromised hosts and prolonged survival of these patients, a recent increase in the incidence and spectrum of opportunistic infections has been observed [114]. The risk of infection in recipients of SOT is mostly related to: (1) the epidemiological exposures of the individual, and (2) the net state of immunosuppression $[104,114]$. The net state of immunosuppression is determined by interaction of the following: (1) the type, dose and duration of immunosuppressive therapy administered, (2) the underlying disease and the comorbid medical conditions, (3) presence of devitalized tissues or fluid collection in the transplanted body organ, (4) presence of indwelling devices such as central venous catheters, (5) other host factors that increase the susceptibility to infections such as: neutropenia, hypogammaglobulinemia, diabetes mellitus, uremia, malnutrition, and (6) concomitant viral infections such as Epstein-Barr virus and cytomegalovirus (CMV) [114].

Immunosuppression following SOT enhances the risk of infection by: (1) increasing the risk of tissue invasion, (2) increasing the risk of dissemination and superinfection, and (3) blunting or masking the typical inflammatory responses that are usually encountered in immune competent individuals [104]. Related to the risks of infection by specific microorganisms, the post-transplant period is divided into three periods: (1) the early post-transplant period (the first month), (2) the intermediate post-transplant period (1-6 months) and (3) the late post-transplant period which is the time when the transplant recipients suffer the greatest impact of immunosuppression and consequently are at the highest risk of developing opportunistic infections [114].

\section{Pre-transplant screening and evaluation}

Pre-transplant screening of potential donors and recipients of SOT is essential to the success of SOT [115]. Diagnostic testing and management of infectious complications in recipients of SOT must be guided by: (1) culture of the organism from various sites in addition 
to tissue histology, (2) serological tests which indicate exposure to pathogens, and (3) vulnerability of SOT recipients to infections with drug-resistant organisms [114]. The goals of pre-transplant infectious disease screening are: (1) identification of conditions that may disqualify the donor or the recipient, (2) identification and treatment of active infections in the pre-transplant period, (3) definition of the risk of infection, and (4) implementation of appropriate preventive interventions [115].

Pre-transplant evaluation should include inquiry about history of: (1) specific infections and the treatments administered, (2) travel, (3) environmental exposures, (4) animal exposures in case of zoonotic infection such as brucellosis, and (5) infection prevention approaches and updating of immunization [115]. Health education and provision of printed material are essential in the prevention strategies of infections [115]. Absolute prevention of the transmission of donor-derived infections in SOT is not possible, but improvement in screening technologies will enhance the safety of SOT in the future [113]. Future advances will likely include: (1) the utilization of rapid molecular diagnostic procedures particularly for fastidious organisms such as Brucella species, and (2) possibly, additional testing for newly emerging pathogens such as Swine Flu virus (H1N1) and Corona virus infections [115].

\section{Donor-derived infections:}

Donor-derived infections can be acquired if the donor has any bloodstream infection at the time of donation [114]. However, there is general agreement on screening for major infections, but there is some variation between transplant centers regarding the type of screening used and the action to be taken once the results of screening are available [115].

The risk of transmission of infection by the allograft is largely unknown and can be difficult to assess for a specific organ that is donated. The approach to screening of organ donors varies according to the: (1) national and regional regulations, (2) availability of certain microbiological assays or tests in the transplantation center, and (3) epidemiology of infections in the region, particularly endemic infections such as brucellosis [113]. The infections that can be transmitted by SOT are included in Table 1, [104,105,114-117].

\section{Post-transplant infections}

The goals of patient care following SOT are: (1) prevention of transmission of donor-derived infections, (2) early recognition of infections in recipients of SOT, and (3) early intervention once an infection is strongly suspected [104]. The diagnosis and treatment of infectious complications following SOT are often delayed because: (1) presentation of infection may be atypical, and (2) presentation of infection may be complicated by allograft rejection [104]. It is desirable to obtain blood cultures from living SOT donors and once positive blood cultures are obtained, thorough investigations should be performed, with particular attention paid to endemic infections such as brucellosis [104].

Infectious pathogens may be carried by the graft or by transfusion of blood products during or after transplantation [117]. Transmission of tropical infectious diseases occurs through 3 main routes: (1) donor-derived infections, (2) reactivation of old or latent infections such as tuberculosis or brucellosis, or (3) de novo transmission occurring during the post-transplant period. Also, infections caused by bacterial pathogens can occur once corticosteroids, mycophenolate mofetil and rituximab are prescribed [114,117].

\section{Tropical infections in SOT recipients}

The risk of acquiring tropical infectious diseases varies with: (1) the destination of travel, (2) the type of exposure, (3) the purpose of the trip, (4) the level of accommodation, hygiene and sanitary level, and (5) the behavior of the transplant traveler [105]. The number of reports of tropical infections in SOT recipients is growing due to: (1) increasing travel of transplanted recipients to the tropics and subtropics, (2) increasing immigration of populations from endemic areas for tropical infections to non-endemic areas, (3) increasing numbers to transplantation procedures taking place in tropical countries, and (4) transplant tourism as many patients travel overseas to countries having high prevalence of tropical diseases [105]. It is essential to encourage SOT recipients travelling to high-risk areas to seek expert advice regarding preventive strategies and vaccines [105]. Some tropical infectious diseases may increase the risk of organ transplant rejection [105]. Uncomplicated as well as complicated infections, such as Brucella endocarditis and neurobrucellosis, have been reported in recipients of SOT [105,118,119].

\section{Reported cases of brucellosis in recipients of SOT}

Brucellosis has been reported in recipients of SOT. However, it is more frequent in renal transplant recipients than in recipients of liver transplantation. Brucellosis can develop as early as 2 months and as late as 17 years post SOT [105,117,118,120-123]. The sources of Brucella infections in recipients of SOT include: (1) donor-derived infection, (2) blood transfusion-related infection, (30 reactivation of old infection due to the immunosuppressive therapy administered to prevent graft rejection, and (4) new infection in these patients who are vulnerable to various infectious complications due to their immunocompromised status [105,118,122-125].

The following complications have been reported in SOT recipients: Brucella arthritis, neurobrucellosis, paraspinal abscess, Brucella endocarditis, Brucella bacteremia in addition to hematological and hepatobiliary complications [105,118,120-123]. Brucellosis in recipients of SOT responds well to various combinations of the following antimicrobials: doxycycline, rifampicin, ciprofloxacin and TMP/SMZ. However, complicated infections may require not only prolonged courses of antimicrobials for 6 to 12 weeks but also surgical intervention, particularly in the presence of $\mathrm{BE}$ or abscess formation $[117,120,121,123]$. Tigecycline is a potential therapeutic option in the treatment of brucellosis in SOT recipients [123]. Drug interactions between antimicrobials and immunosuppressive therapies have to be taken into consideration in recipients of SOT being treated for brucellosis [123].

\section{Prevention of infections in SOT}

The risk of donor-derived infection can be reduced by: (1) improving donor screening, (2) analysis of exposure history, and (3) acquiring advanced molecular biology-based diagnostic testing 
Table 1: Infections transmitted by SOT and HSCT.

\begin{tabular}{|c|c|c|c|}
\hline Type of infection & \multicolumn{2}{|l|}{ SOT } & \multirow{2}{*}{$\begin{array}{l}\text { HSCT } \\
\text { - Contaminants } \\
\text { - Brucella species }\end{array}$} \\
\hline Bacteria & $\begin{array}{l}\text { - Staphylococcus aureus } \\
\text { - Klebsiella species } \\
\text { - Bacteroides fragilis } \\
\text { - Pseudomonas aerugin } \\
\text { - Escherichia coli } \\
\text { - Yersinia enterocolitica }\end{array}$ & $\begin{array}{l}\text { - Salmonella species } \\
\text { - Brucella species } \\
\text { - Bartonella species } \\
\text { - Enterobacter species } \\
\text { - Acinetobacter species } \\
\text { - Treponema pallidum } \\
\text { - Leptospira species }\end{array}$ & \\
\hline Mycobacteriae & \multicolumn{2}{|c|}{$\begin{array}{l}\text { - Mycobacterium tuberculosis } \\
\text { - Mycobacterium leprae } \\
\text { - Non-tuberculous Mycobacteriae }\end{array}$} & $\begin{array}{l}\text { - Mycobacterium tuberculosis } \\
\text { - Mycobacterium leprae } \\
\text { - Non-tuberculous Mycobacteriae }\end{array}$ \\
\hline $\begin{array}{l}\text { Parasites and } \\
\text { protozoa }\end{array}$ & $\begin{array}{l}\text { - Plasmodium species } \\
\text { - Schistosoma species } \\
\text { - Giardia lamblia } \\
\text { - Taenia solium } \\
\text { - Entamoeba histolytica }\end{array}$ & $\begin{array}{l}\text { - Wuchereria bancrofti } \\
\text { - Toxoplasma gondii } \\
\text { - Trypanosoma cruzi } \\
\text { - Strongyloides stercoralis } \\
\text { - Pneumocystis jiroveci pneumonia }\end{array}$ & $\begin{array}{l}\text { - Pneumocystis jiroveci pneumonia } \\
\text { - Plasmodium species } \\
\text { - Toxoplasma species } \\
\text { - Babesia species } \\
\text { - Leishmania species }\end{array}$ \\
\hline Prions & \multicolumn{2}{|l|}{ |------------ } & - Creutzfeld-Jacob disease \\
\hline Viruses & $\begin{array}{l}\text { - Cytomegalovirus } \\
\text { - Epstein-Barr virus } \\
\text { - Adenovirus } \\
\text { - Influenza virus } \\
\text { - Parainfluenza virus } \\
\text { - Metapneumovirus } \\
\text { - Varicella-zoster virus } \\
\text { - Herpes Simplex virus } \\
\text { - Parvovirus } B_{19} \text { virus } \\
\text { - Rabies virus } \\
\text { - Dengue virus } \\
\text { - West Nile virus }\end{array}$ & $\begin{array}{l}\text { - Hepatitis viruses: B,C and D } \\
\text { - SARS, Corona virus } \\
\text { - Respiratory syncytial virus } \\
\text { - Human immunodeficiency virus } \\
\text { - Human T cell lymphotrophic virus } \\
\text { - Lymphochoriomeningitis virus } \\
\text { - Human Herpes viruses: } \\
\text { 6,7 and } 8\end{array}$ & $\begin{array}{l}\text { - Cytomegalovirus } \\
\text { - Epstein-Barr virus } \\
\text { - Human T cell lymphotrophic virus } \\
\text { - Human immunodeficiency virus } \\
\text { - Hepatitis viruses: B,C and D } \\
\text { - Respiratory syncytial virus } \\
\text { - Adenovirus } \\
\text { - Parvovirus B19 } \\
\text { - West Nile virus } \\
\text { - Metapneumovirus } \\
\text { - Influenza virus } \\
\text { - Parainfluenza virus }\end{array}$ \\
\hline
\end{tabular}

[117]. Occupational exposure should be avoided, particularly during the first 6 months after transplantation [117]. Education of transplant recipients before and after transplantation regarding zoonotic risks may further decrease zoonotic infection in these immunocompromised individuals. Unfortunately, the live-attenuated Brucella animal vaccine has the potential to cause disseminated disease in immunocompromised humans [117].

\section{Brucellosis in recipients of HSCT}

Transmission of bacteria to a recipient of HSCT usually occurs through: (1) contamination of the graft, (2) blood of the donor, (3) bone marrow of the donor, and (4) blood product transfusions in the post-HSCT period $[29,57,100,105,116-118,126-128]$. The reported contamination rates of about 1 per 3000 units as observed in blood products seem to be excessive in the absence of definitive information and data from other studies [116]. Cryopreserved autologous grafts or cord blood may be contaminated with Gram-positive bacteria or less frequently with Gram-negative bacteria [116]. With the increase in donor age, the potential of transmitting diseases from donors to recipients reaches new dimensions [116]. The potentially transmittable diseases from HSCT donors include: (1) infections caused by various micro-organisms as shown in Table 1, [104,105,113,115-117], (2) congenital diseases such as thalassemia, (3) autoimmune disorders such as autoimmune thrombocytopenia, and (4) malignancies such as leukemia and lymphoma [116]. Donor-derived infections caused by viruses, fungi, parasites, Mycobacteriae and several other bacteriae including Brucella species have been reported in recipients of HSCT [104,105,113,115-117,126-128]. One of the prerequisites for donating hematopoietic stem cells is to have a healthy donor who will pass all screening tests for various infections [128]. Once a certain infection is diagnosed in a potential donor for HSCT, it has to be treated appropriately before reconsidering the donor again [128]. Identification of donors at high risk of transmittable infections is essential and HSCT donors should have thorough evaluation and detailed history [116]. Brucellosis is not routinely screened for in the western countries, but donor screening for brucellosis is of vital importance in endemic areas [116]. Evaluation of donor-transmitted complications within the established registries is urgently needed and systemic monitoring of incidence, severity and outcome of donor related complications including infections is essential [116].

Most zoonotic infections occur as a primary infection after transplantation and hence immunocompromised individuals are likely to experience significant morbidity and mortality [117]. Donors 
and recipients of HSCT are at risk of acquiring zoonotic infections such as brucellosis due to immigration, foreign travel and exotic pets [117]. Detailed medical history including risk factors for Brucella infection should be obtained during the pre-donation period of time and before clearing the donor [127]. Brucella serology is usually performed during the period of donor evaluation within at least 30 days prior to stem cell donation [127]. Brucellosis in a donor of HSCT should be treated and the donor should not be allowed to donate stem cells till at least two years after full recovery from the infection [128]. Brucella infections have been: (1) transmitted to recipients of HSCT through allografts harboring Brucella species, and (2) reported in recipients of HSCT after achieving successful engraftment [29,57,100,105,116-118]. In recipients of HSCT living in endemic areas, brucellosis and Brucella bacteremia can develop at any stage of their illness $[29,100,126]$. In these patients, brucellosis usually presents with fever and various degrees of cytopenias [100]. The administration of appropriate antimicrobials will control the infection and prevent further complications [100]. Although brucellosis can be treated successfully with antibiotics, donors and recipients living in endemic areas should be appropriately screened for brucellosis [116].

\section{Brucellosis in pregnancy}

In endemic areas, the cumulative incidence of brucellosis in pregnant women may reach 1.3 per 1000 obstetric deliveries [38,129]. Brucellosis in pregnancy can present in an acute, subacute or a chronic manner [106]. The clinical manifestations of brucellosis in pregnant females are similar to those in the general population [129]. Occasionally, it may be complicated by Brucella bacteremia, septic shock, neurobrucellosis and disseminated intravascular coagulation (DIC) [131,132]. Brucellosis in pregnancy may predispose to spontaneous abortion, intrauterine fetal death, premature delivery, low birth weight in addition to postpartum intrauterine infections [1,130,133-139]. Vaginal bleeding at presentation may be an early sign of spontaneous abortion. Unfortunately, delivery of pregnant women having brucellosis may cause infection of the delivery team $[38,138]$.

Presence of carbohydrate erythritol in the animal placenta appears to be a preferential growth medium for Brucellae in animals. Consequently, brucellosis causes fewer spontaneous abortions in humans than in animals $[132,140]$. The presence of anti-Brucella activity in the amniotic fluid and the absence of erythritol in human placenta are believed to protect against abortion. Nevertheless, positive Brucella cultures have been obtained from the products of conception such as the human placenta and the aborted fetuses $[137,140]$. In pregnant females having brucellosis and living in areas that are endemic for the disease, the incidence of spontaneous abortion ranges between $24 \%$ and $53 \%$ while positive Brucella serology may be encountered in less than $3 \%$ of pregnant women $[38,130,134]$. Brucella seropositivity is not more common in women with spontaneous abortion or miscarriage than in women with uncomplicated pregnancies [141,142]. Some studies have shown that there is no correlation between the magnitude of Brucella agglutination titer and the occurrence of spontaneous abortion while others have shown that Brucella titers higher than 1:160 are associated with higher probability of spontaneous abortion [38,130,136,143].

Brucellosis in pregnancy should be treated as soon as the diagnosis is made so as to prevent the evolution of complications $[130,133,137]$. There are no randomized trials on the treatment of brucellosis in pregnancy, but the combination of TMP/SMZ and rifampicin is the most commonly used regimen $[1,130,134,137]$. Nevertheless, brucellosis in pregnancy has been successfully treated with single agents such as rifampicin or TMP/SMZ, although monotherapy is usually associated with high relapse rates $[38,133,138,141,144]$. The optimal duration of antimicrobial therapy is 6 weeks and the success rate of antibiotic treatment for brucellosis in pregnant women may reach 90\% [129,138,141]. Screening programs for brucellosis in pregnant women living in endemic areas and health education of the target populations are recommended [141,142,145]. Brucellosis should be included in the differential diagnosis of fever in pregnant females living in endemic [141,142].

\section{Brucellosis in patients with hematological disorders:}

Brucellosis has been reported in patients with a variety of hematological diseases such as: acute myeloid leukemia, acute lymphoblastic leukemia, myelodysplastic syndrome, multiple myeloma, polycythemia rubra vera and myelofibrosis $[99,106-$ 109,146-150]. In patients with malignant and pre-malignant hematological disorders living in endemic areas, brucellosis can cause: febrile illnesses; pancytopenia; systemic infections including endocarditis, meningoencephalitis, pulmonary insufficiency and splenic abscess; complicated bacteremia and serious morbidity [61,99,106-109,150,151] Additionally, several cases of febrile neutropenia caused by infection with Brucella species have been reported in patients with malignant hematological disorders living in geographic locations that are endemic for brucellosis [147-149,152-156]. Brucellosis may develop at presentation of the hematological malignancy or even if the disease is under control $[99,150,151]$. Presentation of brucellosis is usually with fever and pancytopenia, although some patients may present with clinical manifestations similar to those in immunocompetent individuals $[99,106,107,146,150,151]$. Early diagnosis of brucellosis and prompt administration of appropriate antimicrobial therapy usually improve the outcome in such immunocompromised individuals $[99,150,151]$. Antimicrobial drug therapy can be administered simultaneously with cytotoxic chemotherapy to control both brucellosis and hematological disorders but in case of bacteremia, prompt antimicrobial therapy may become essential $[99,150,151]$.

\section{Brucellosis and renal disease}

Brucellosis has been reported in patients with end stage renal disease (ESRD) living in endemic areas [157,158]. Presentation is usually with FUO but the infection may be complicated by neurobrucellosis, paravertebral and epidural abscesses and peripheral arthritis $[157,158]$. Brucellosis has been reported to cause ESRD, pyelonephritis, interstitial nephritis, mixed cryoglobulinemia and IgA nephropathy [159]. Tissue biopsies in patients having renal involvement by brucellosis have shown: mesangial and diffuse proliferative glomerulonephritis, rapidly progressive and focal segmental glomerulonephritis as well as exudative glomerulonephritis [159]. Antimicrobial therapy given for brucellosis usually improves 
the renal involvement [159].

\section{Brucellosis in patients with HIV infection}

Despite the apparent poor association between HIV and brucellosis and that the impression that HIV infection does not seem to increase the incidence of brucellosis, several cases as well as case series on the development of brucellosis in HIV infected individuals have been reported [86,160-166]. The risk factors for Brucella infection in HIV patients are male sex and intravenous drug abuse [162,163]. Clinical presentation is usually with fever, sweating, arthralgia and myalgia. Focal disease and recurrence of symptoms, but not disease relapse, may occur and high Brucella serological titers are usually encountered [163]. Brucellosis is not an opportunistic infection in patients with HIV or acquired immunodeficiency syndrome even in endemic areas and most HIV patients co-infected with Brucella species have benign clinical course of their brucellosis $[1,162]$

\section{Brucellosis coexisting with other infections}

Brucellosis has been reported in patients having other infections such as leishmaniasis, tuberculosis, hepatitis $\mathrm{C}$ infection and viral hemorrhagic fevers. Cytopenias are major complications in these patients. The development of further complications can be prevented by simultaneous treatment of both infections and provision of supportive measures $[95,166-171]$

\section{Brucellosis coexisting with other chronic medical illnesses}

Brucellosis has also been reported in patients having chronic medical illnesses such as chronic osteoarthritis, polycythemia rubra vera, liver cirrhosis, pulmonary fibrosis and rheumatoid arthritis (RA). Early institution of appropriate antimicrobial therapy is essential to control Brucella infection and to prevent complication $[172,173]$.

Approximately $40 \%$ of patients having brucellosis develop systemic and chronic manifestations similar to those of chronic fatigue syndrome or myalgic encephalomyelitis [101]. Also, patients infected with Brucella species may present with neurological manifestations indistinguishable from those of with multiple sclerosis. However, old and new literatures provide conflicting data on the association between brucellosis and multiple sclerosis [102,174,175].

\section{Brucellosis and solid tumors}

It has been postulated that tumor formation might be associated with chronic brucellosis [103]. The DNA of Brucella species has been identified in CNS tumors such as medulloblastomas. Therefore, further studies are required to explore the true association between tumor formation in the CNS and the DNA positivity of Brucella species [103]. In patients having brucellosis and solid tumors, treatments of both brucellosis and the primary cancer should be administered to control both disorders [176].

Brucellosis may coexist not only with solid tumors but also with other infections such as tuberculosis as the clinical and radiological manifestations of cancer and chronic infections may overlap $[103,110,111,176]$. Brucellosis has been reported to coexist with the following solid tumors: (1) medulloblastoma and glioblastoma multiforme as both can resemble neurobrucellosis, (2) lung carcinoma as pulmonary tuberculosis and respiratory brucellosis can give rise to similar lesions, (3) ovarian cancer as tubo-ovarian brucellosis can give rise to similar manifestations, (4) prostatic cancer as brucellosis can cause prostatitis, prostatic swelling and abscess formation, and (5) hepatocellular carcinoma as brucellosis can cause single and multiple hepatic nodular lesions [103,110,111,176,177]. However, the following can help in differentiating brucellosis from solid tumors: (1) the clinical manifestations based on careful and detailed history as well as comprehensive physical examination, (2) positive serological testing for brucellosis, although serological tests may not be entirely reliable in patients with cancer, (3) positive molecular assays for brucellosis such as PCR, (4) positive cultures of brucellosis that can be obtained from blood, peritoneal fluid, pleural fluid, bronchoalveolar lavage, cerebrospinal fluid and fluid taken from abscess collection, (5) granulomatous changes on histopathology, and (6) negative tumor markers $[103,110,111,176]$.

\section{Brucellar epidedymo-orchitis and testicular cancer}

Epidedymo-orchitis (EO) is the commonest urological manifestation of brucellosis [178]. It occurs predominantly in young individuals and it presents with testicular swelling or mass, abscess formation, testicular atrophy and pain which may be absent [179182]. The typical features of Brucella-related EO include: presence of an occupational risk factor, seasonal incidence, gradual onset, long duration of clinical manifestations, typical undulant fever, absence of severe leukocytosis, absence of lower urinary tract symptoms, relatively minimal signs of florid inflammation, unilateral involvement in most cases and relapses which are rarely encountered $[178,183,184]$. Mild to moderate leukocytosis is usually present and CRP is usually elevated [178]. Histology of the testis may reveal inflammatory changes, abscess formation, atrophy and fibrosis in addition to granulomatous changes [179,180,182].

Clinical data based on careful history and meticulous physical examination in addition to laboratory findings based on serological assays are usually sufficient to make the diagnosis of Brucellarelated EO [183]. However, early detection and appropriate therapy of Brucella-related EO are essential and brucellosis should be considered as a possible cause of EO and testicular swellings [184]. Also, Brucella-related EO should be included in the differential diagnosis of testicular tumors in patients living in areas that are endemic for the disease [178-183] In patients with EO caused by brucellosis, conservative management in the form of combination of antibiotics is usually adequate $[178,183,184]$. Unfortunately, patients with Brucella-related EO may undergo unnecessary orchiectomy as the initial suspicion may be testicular carcinoma [179,180,182].

\section{Brucellosis and rheumatic diseases}

Infections in patients with rheumatic diseases cause significant morbidity and mortality [185]. Unfortunately, the diagnosis or recognition of infections in patients with rheumatic diseases may be difficult and delayed due to the following reasons: (1) the clinical manifestations of certain infections such as brucellosis may be indistinguishable from those of the underlying disease, and (2) the typical signs and symptoms of these infectious complications may be 
atypical or entirely absent [185]. Patients with rheumatic disorders are susceptible to infections with various micro-organisms, particularly bacteria and opportunistic agents due to the following factors: (1) the underlying rheumatic disorders, and (2) the administered immunosuppressive agents such as: corticosteroids, azathioprine, cyclophosphamide, anti-TNF therapy such as infliximab and targeted therapies such as rituximab [173,185-187].

TNF plays an important role in the host defense mechanisms and anti-TNF therapies may increase the risk of infections in patients with rheumatic diseases [173]. Brucellosis should be kept in mind, particularly in endemic areas, in patients receiving anti-TNF therapies as brucellosis has been reported in patients with RA receiving infliximab $[173,186,187]$. In patients with RA, infection is a major comorbidity and is related to the immunosuppressive therapies given and to the intrinsic effects of RA on certain body organs specifically the musculoskeletal system, while in patients with systemic lupus erythromatosis, infection is a cause of hospital admission and is a leading complication following admission [185].

\section{Diagnosis of brucellosis}

The laboratory tests that are used in the diagnosis of brucellosis include:

(1) Microbiological cultures: isolation of the organism from clinical samples such as blood, bone marrow, pus and tissues. Cultures give a low yield rate and identification of the organism and subsequent susceptibility testing take time, so treatment of brucellosis may be delayed [188].

(2) Serological tests: several serological techniques are used and these include: Coomb's test, slide or tube agglutination, enzymelinked immunosorbent assay (ELISA), immunocapture agglutination, immunochromatographic lateral flow, Brucella-Capt, and indirect fluorescent antibody test as shown in Table 2, [63]. Serological tests are more useful but not internationally standardized [188]. Antibodies may remain elevated despite successful treatment, crossreactions may occur and different cut-offs are needed for various levels of endemicity [188].

(3) Molecular assays: these include RT-PCR. Molecular tests may reduce the time to reach diagnosis, but diagnostic criteria for active infection have not been defined [188]. Each of the above tests has advantages and limitations. Therefore, interpretation of their results should be made carefully and in conjunction with the available clinical data [63].

\section{Hematological abnormalities in brucellosis}

Hematological abnormalities in brucellosis include: leukopenia with relative lymphocytosis, neutropenia, anemia, thrombocytopenia, pancytopenia, DIC, microangiopathic hemolytic anemia (MAHA), hypersplenism, and elevation of ESR as well as CRP $[1,61,189,190]$. However, none of these hematological abnormalities is specific or characteristic for brucellosis [190].

Thrombocytopenia is occasionally encountered and may be severe. Thrombocytopenic purpura has also been reported in patients

\begin{tabular}{|c|c|}
\hline Test & Details \\
\hline Rose Bengal test & $\begin{array}{l}\text { - Agglutination test based on reactivity of antibodies against } \\
\text { smooth lipopolysaccharide (LPS). } \\
\text { - High sensitivity and rare false positive results. } \\
\text { - The present WHO guidelines recommend confirmation of } \\
\text { this test by other assays such as } \\
\text { serum agglutination test. }\end{array}$ \\
\hline Coombs test & $\begin{array}{l}\text { - Used for detection of incomplete, blocking and non- } \\
\text { agglutinating immunoglobulin } \mathrm{G}(\mathrm{lgG}) \text {. } \\
\text { - It is time consuming and technically difficult as it requires } \\
\text { skilled personnel. } \\
\text { - It is not routinely performed in clinical laboratories. } \\
\text { - However, it is the most suitable and sensitive test for } \\
\text { confirmation of complicated, relapsing } \\
\text { and chronic cases. }\end{array}$ \\
\hline $\begin{array}{l}\text { Fluorescence } \\
\text { polarization test }\end{array}$ & $\begin{array}{l}\text { - Valuable alternative to conventional serological tests. } \\
\text { - Sensitivity: } 96 \% \text { for culture confirmed brucellosis. } \\
\text { - Specificity: } 98 \% \text {. }\end{array}$ \\
\hline ELISA test & $\begin{array}{l}\text { - There are } 3 \text { available ELISA assays: (1) IgG, IgA and IgM } \\
\text { antibody tests, (2) the standard } \\
\text { tube agglutination test [SAT], and (3) 2-mercaptoethanol } \\
\text { test [2-MET]. } \\
\text { - SAT is the gold standard ELISA assay for the diagnosis of } \\
\text { brucellosis particularly in endemic areas. } \\
\text { - ELISA is an excellent method for: screening large } \\
\text { populations for Brucella antibodies } \\
\text { and differentiation between acute and chronic cases. } \\
\text { - ELISA is the test of choice for complicated and chronic } \\
\text { cases particularly when the diagnosis is } \\
\text { highly suspected and other tests are negative. }\end{array}$ \\
\hline $\begin{array}{l}\text { Immunocapture } \\
\text { agglutination } \\
\text { test, Brucella } \\
\text { Capt (BCAP) }\end{array}$ & $\begin{array}{l}\text { - Can detect agglutinating and non-agglutinating antibodies } \\
\text { with high sensitivity. } \\
\text { - Easy to perform within } 24 \text { hours, but is expensive. } \\
\text { - Based on the immunocapture-agglutination of the total anti- } \\
\text { Brucella antibodies. } \\
\text { - Can be used as a second level serological test in } \\
\text { brucellosis. }\end{array}$ \\
\hline Dipstick assay & $\begin{array}{l}\text { - The IgM dipstick assay is one of the tests that have been } \\
\text { adapted to detect IgM antibodies to small LPS. } \\
\text { - The assay has high sensitivity for brucellosis lasting less } \\
\text { than } 3 \text { months. }\end{array}$ \\
\hline $\begin{array}{l}\text { Lateral flow } \\
\text { assay }\end{array}$ & $\begin{array}{l}\text { - It is a simplified version of the ELISA test. } \\
\text { - It detects Brucella IgM and IgG antibodies by an } \\
\text { immunochromatographic method. } \\
\text { - It is rapid, simple and easy to perform. } \\
\text { - It uses a drop of blood obtained by a finger prick and can } \\
\text { be performed at the bedside. }\end{array}$ \\
\hline $\begin{array}{l}\text { Rapid slide } \\
\text { agglutination test }\end{array}$ & $\begin{array}{l}\text { - It is a suitable screening test for the diagnosis of human } \\
\text { brucellosis. } \\
\text { - It can detect human infection with } B \text {. canis. }\end{array}$ \\
\hline
\end{tabular}

with brucellosis. Early recognition of this complication is essential as CNS hemorrhage is associated with high mortality rates. Nevertheless, treatment of brucellosis in addition to corticosteroid therapy can control both disorders [191,192]. Hemolytic anemia that may be acute and Coomb's positive can also be seen [4,193-199]. Despite the severity of MAHA, complete recovery has been encountered with early and prompt therapy using plasma exchange, antimicrobial therapy for brucellosis and corticosteroids [200-203]. Capillary leak syndrome, similar to that occurring as part of graft versus host disease following HSCT, has been reported in patients with brucellosis [204]. Patients may present with: fever, sweats, weakness, hepatosplenomegaly, 
peripheral edema, pancytopenia, hypoalbuminemia and elevation of liver enzymes. Anti-Brucella therapy usually results in the resolution of the clinical and the laboratory manifestations [204].

In patients living in areas that are endemic for brucellosis, presentation with FUO and pancytopenia should alert treating physicians to the possibility of having an underlying primary hematological disorder such as myelodysplastic syndrome or myelofibrosis $[106,146]$ In patients having brucellosis and hematologic malignancy, simultaneous treatment of both the infection and the hematologic malignancy should be considered [61].

Bone marrow examination in brucellosis may show the following findings: (1) normocellular, hypercellular or hypocellular marrow, (2) granuloma formation, (3) hemophagocytosis with histiocytic hyperplasia, (4) erythroid hyperplasia, and (5) infiltration by plasma cells or leukemic blasts on very rare occasions as shown in Table 3, [61,189,205,206]. Brucellosis causes granulomas in the bone marrow and other tissues and these granulomas are usually small, non-caseating and they resemble sarcoid granulomas $[46,61,189]$. Histologically, they consist of epitheloid cells, polymorphonuclear leukocytes, lymphocytes and few giant cells as shown in Table 3, [46,205-208].

\section{Brucella cultures}

Brucella species can be cultured from blood, bone marrow, other tissues and body fluids such as liver, skin and pleural fluid [208-213].

\section{Blood cultures in brucellosis}

In patients with brucellosis, the range of blood culture positivity varies from $6 \%$ to $92 \%$ of patients depending on the following factors: (1) stage of the disease: acute, subacute or chronic, (2) the levels of Brucella titers, (3) the microbiological culture technique utilized and (4) prior antimicrobial therapy [23,208-210]. Isolation of these intracellular organisms from blood cultures is restricted by the slow growth of Brucella species and by the effect of previous antimicrobial

Table 3: Differential diagnosis of brucellosis based on bone marrow (BM) histology.

\begin{tabular}{|l|l}
\hline BM granulomas & BM hemophagocytic lymphohistiocytosis \\
\hline 1- Bacterial infections: & \\
- Mycobacterium & \\
tuberculosis & \\
- Typhoid fever & 1- Viral infections: \\
- Tularemia & Epstein-Barr virus, Cytomegalovirus, Herpes \\
- Syphilis & Simplex \\
- Leprosy & virus, Varicella-zoster virus, Human \\
2- Fungal infections: & Immunodeficiency \\
- Histoplasmosis & virus, Hepatitis virus, Adenovirus, Influenza virus, \\
- Cryptococcosis & Parvovirus, Human Herpes viruses types 6 and 8. \\
- Coccidioidomycosis & 2- Other infections: \\
3- Rickettsial infections: & Mycobacteria, spirochetes, parasites and fungi. \\
- Q fever & 3- Malignancy such as lymphoma. \\
4- Viral infections: & 4- Macrophage activation syndrome \\
- Cytomegalovirus & associated with \\
- Epstein-Barr virus & autoimmune diseases. \\
- Varicella-zoster virus & \\
5- Parasitic infections: & \\
- Leishmaniasis & \\
- Toxoplasmosis & \\
&
\end{tabular}

chemotherapy [208,209].

There are three main types of culturing techniques: (1) the traditional Ruiz-Castaneda method, (2) the automated culture systems and (3) the yield-optimizing methods including the lysis concentration technique [214,215]. Once a fastidious organism such as Brucella species is suspected, extension of the incubation period of blood cultures for days to weeks is usually needed to improve the yield rates of the traditional methods [214-216]. Additionally, the utilization of various automated culture systems has significantly decreased the period of time required to obtain a positive culture and has improved the yield rates [214,215].

\section{Cultures of bone marrow and other body fluids}

Bone marrow examination and Brucella cultures of the marrow aspirate are indicated under the following circumstances: (1) in patients strongly suspected to have brucellosis on clinical grounds but have negative serological tests, (2) in patients with FUO, particularly in geographic locations that are endemic for the disease, (3) in patients having unexplained articular or hematological involvement who live in endemic areas, and (4) in areas where advanced facilities such as automated culture systems or molecular techniques are not readily available $[207,208,213,217]$.

Bone marrow culture for Brucella species may be positive more frequently than blood cultures and may be positive in the absence of positive Brucella serology or blood cultures. The yield of bone marrow cultures may reach $92 \%$ in patients who are strongly suspected to have brucellosis [210]. However, in a study that included 102 patients having brucellosis, the yield rates of blood cultures compared to bone marrow cultures were as follows: $66 \%$ versus $46 \%$ in acute brucellosis, $31 \%$ vs $21 \%$ in subacute infection and $0.0 \%$ vs $8.0 \%$ in chronic brucellosis, while the overall yield rates were $38 \%$ compared to $34 \%$ [210]. In addition to bone marrow cultures and in order to increase the yield of positive cultures, it is also recommended to try to culture aspirates or fluids obtained from: liver, lymph nodes, pleural space, bronchoalveolar lavage, joints and skin lesions in areas that lack advanced technology to diagnose brucellosis [214].

\section{Serology in the diagnosis of brucellosis:}

Several serological tests are available for the diagnosis of brucellosis $[63,188]$. However, they vary considerably regarding several aspects including: applications in various situations and usefulness as reflected their sensitivity and specificity as shown in Table 2, [49,63,188,217-230].

\section{New biomarkers of brucellosis}

Brucellosis may mimic rheumatoid arthritis clinically. Positive serological tests for rheumatic and autoimmune diseases such as rheumatoid factor (RF) and antinuclear antibody (ANA) are encountered in a relatively high proportion of patients with brucellosis [231]. Therefore, in endemic locations for brucellosis, interpretation of positive serology for rheumatic and autoimmune diseases such as RF and ANA should be taken into consideration. Discrimination between brucellosis and rheumatoid disorders, 
both clinically and serologically, may be difficult in regions that are endemic for brucellosis [231].

In Brucella infections: (1) serum nitric oxide levels are modestly elevated, and (2) IL-6, IL-8 and IL-2R are usually elevated. The extent of elevation of these cytokines depends not only on the severity but also on the clinical pattern of the disease [232]. In patients with Brucella bacteremia or brucellosis with positive bloodstream infection, the following biomarkers of sepsis have been reported to be positive: (1) circulating micro-RNAs (miRs) such as miR-25, miR133a, miR-146, miR-150, and miR-223; and (2) serum pro-calcitonin levels which can be used as surrogate markers to exclude bacteremia $[233,234]$.

\section{Molecular tests in the diagnosis of brucellosis}

PCR is an in vitro technique for nucleic acid amplification which is commonly used to diagnose infectious diseases [235]. The direct culture and immunohistochemistry can be used for detecting infection with Brucella species, but PCR can potentially address the limitations of these procedures [235]. It can be used for pathogen detection, genotyping and quantification and it has the following advantages: high sensitivity and specificity, reproducibility and technical ease. Currently, PCR is one of the most useful assays for the diagnosis of human brucellosis [235]. PCR-based assays allow rapid and more sensitive identification of Brucella at species and biovar levels and their implementation into the clinical setting will likely improve therapeutic outcomes. Unfortunately, the current PCR protocols lack standardization [235,236].

PCR-based testing methods are faster and more sensitive than the traditional methods used in the diagnosis of brucellosis [236]. However, sensitivity, specificity and issues of quality control and quality assurance of the PCR assays vary between laboratories and unfortunately standardization of sample preparation, target genes and detection methods is still lacking [92,236-238]. Early diagnosis and pre-treatment prediction of clinical outcome will have a positive impact on the management of patients with brucellosis [92,236-238].

Combined with serological assays, PCR can be applied for the diagnosis of new cases of brucellosis, asymptomatic but highly exposed individuals in addition to relapsed cases regardless duration or type of the disease without relying entirely on blood cultures, particularly in chronic cases [92,239]. Combined PCR-ELISA technique is an immune-detection method that can directly quantify PCR product as it detects the nucleic acid rather than the protein [240]. It has much higher specificity and sensitivity than PCR alone. Additionally, it is easy to perform, yields results rather quickly and reduces the risk of contamination [240]. It has recently been introduced into the molecular diagnostic techniques of brucellosis and initial results of its use in acute human brucellosis are promising, so it may become a valuable tool to diagnose Brucella infections in immunocompromised hosts in particular [240,241].

\section{Whole genome sequencing and MLVA}

Whole genome sequencing of B. canis strain, BCB018, has been isolated from humans [242]. Also, whole genome sequencing of 10 diagnostic Brucellaphages propagated on 2 B. abortus strains (141 and 519) has revealed: (1) fine scale patterns in the genetic structure of these phages, and (2) multiple common sequence variations across similar genes [243].

Multi-locus variable number tandem repeats (VNTR) assay (MLVA) has the ability to: (1) identify and discriminate between different Brucella species which display significant genetic diversity, (2) be utilized as an epidemiological tool, and (3) be used in brucellosis control and eradication programs [244,245]. The use of MLVA has 2 recent findings: (1) the isolation of $B$. suis from cattle, and (2) the genetic correlation between B. abortus isolates in humans and animals [244,245].

\section{Brucellosis and FUO}

In a study, performed in India, that included 283 patients with FUO: Brucella serology was found to be positive in 3.5-6.0\% of patients having FUO. The incidence of positive Brucella serology varied according to the occupation of the participant and the type of serological test used [246]. In another Indian study on the etiology of FUO, $44 \%$ of patients in whom a cause of FUO was found had infectious etiology and infections were the commonest cause of FUO followed by collagen vascular diseases [247]. The most common infectious causes of FUO are: tuberculosis, endocarditis, typhoid fever, brucellosis, $C M V$ infection and acquired immunodeficiency syndrome in western countries [248]. In patients with FUO, clinical features may give more clues to the diagnosis of collagen vascular disorders, while invasive procedures such as tissue biopsies, followed by cultures and cytology contribute greatly to the diagnosis of cancer and infectious diseases [249].

\section{PET scans in patients with PUO and brucellosis}

Fluoro-18-fluoro-2-deoxy-D-glucose (FDG) accumulates in malignant tissues and at the sites of infection and inflammation [248]. Positron emission tomography (PET)/CAT scans are the procedures of choice for the diagnosis and follow up of certain malignancies particularly lymphomas. The currently available data in the literature indicate that FDG-PET scan is an important second-line procedure in the management of approximately $50 \%$ of patients with FUO and that its utilization in the diagnosis and follow up of several infections is on the rise [248].

In patients with spondylodiskitis due to brucellosis, PET/CAT scans can provide additional information on the spread of infection compared to magnetic resonance imaging. Successful treatment of brucellosis is associated with a significant decrease in the standard uptake value, thus PET/CAT scan may be a complementary method for determining the efficacy of treatment and the need for further antimicrobial chemotherapy [250]. In a patient having pulmonary nodules caused by Brucella infection, increased FDG uptake was encountered not only in the pulmonary lesions, but also in the hilar and mediastinal lymph nodes [251].

\section{Treatment of brucellosis}

The main treatment schedules of human brucellosis, obtained from several meta-analyses and few international recommendations, are shown in Table 4, [15,252-256]. Tigecycline is a new glycylcyclin compound which is more potent than tetracycline. Replacing 
tetracycline by tigecycline may increase the efficacy of anti-Brucella treatment and decrease the duration of anti-Brucella therapy $[257,258]$ Tigecycline has a promising future in the treatment of brucellosis and it may replace tetracycline which is still the mainstay of anti-Brucella treatment. Studies on tigecycline in geographic locations that are endemic for brucellosis have shown excellent in vitro activity and high antimicrobial susceptibility levels [257,258].

Lack of awareness among clinicians, low index of suspicion and non-availability of diagnostic tests can all lead to missed diagnosis of brucellosis [259]. The disease is easily treatable and can be completely cured but failure to diagnose brucellosis early may lead to delayed institution of appropriate antimicrobial therapy and this increases the chances of treatment failure [259]. Having a high index of suspicion, prompt diagnosis and appropriate as well as adequate treatment can cure the patient, prevent chronic morbidity and prevent loss of valuable time to treatment of the infection at an early stage [259]. It has been found that successful management of brucellosis can be

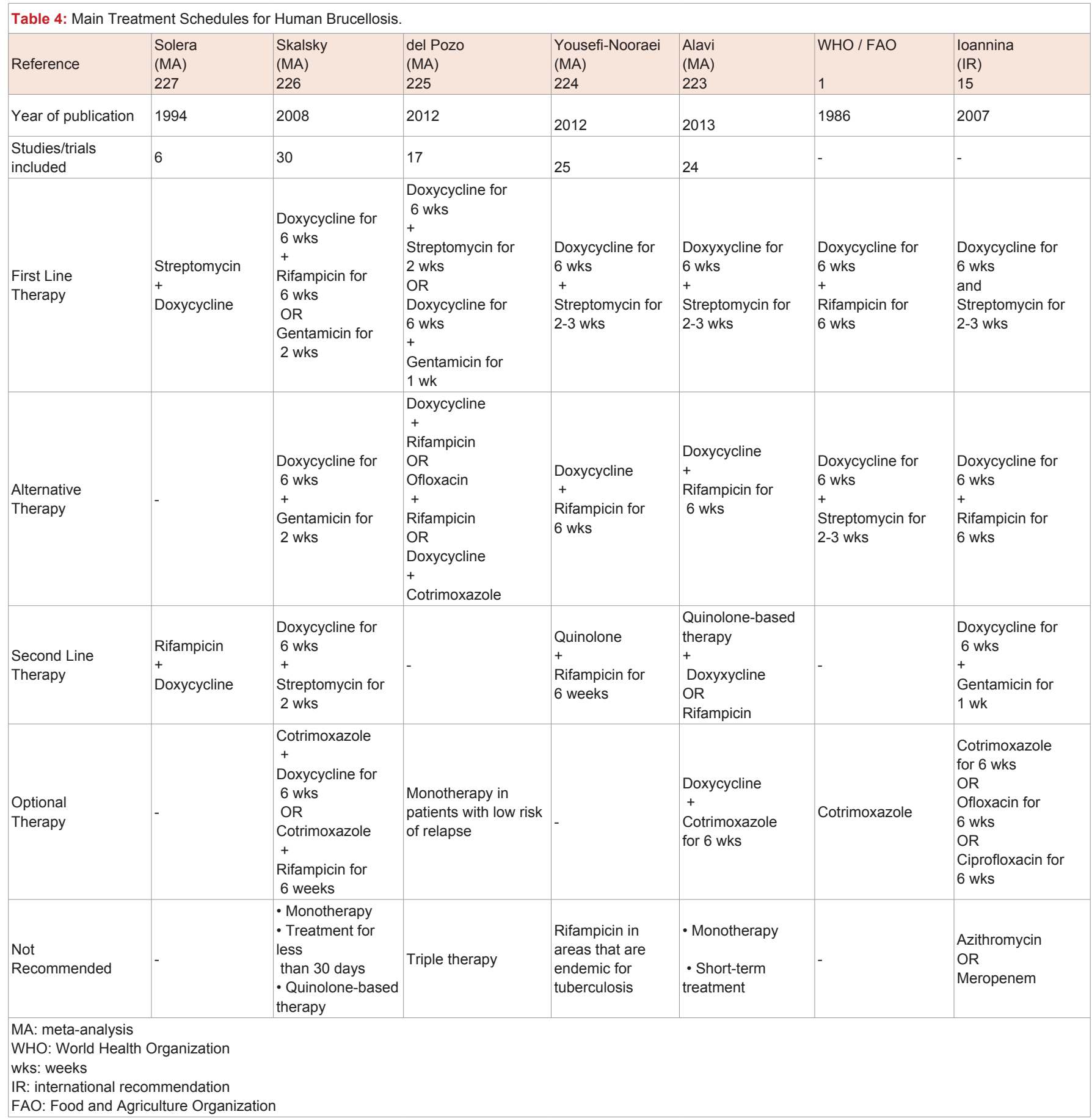


reflected by a decrease in oxidative stress. Hence, it is possible that oxidant and anti-oxidant parameters could be used to monitor the response to treatment in patients with brucellosis [260].

\section{Drug resistance and antibiotic susceptibility}

In order to decrease the development of drug resistance and the incidence of complications of brucellosis, it is important to have antimicrobial therapy guided by antibiotic susceptibility testing [261]. However, antimicrobial susceptibility of Brucella species varies considerably from one place to another [257,258,262-265]. In two studies performed in Turkey 10 and 11 years ago, Brucella species was showing excellent susceptibility to tetracycline, rifampicin, ciprofloxacin and azithromycin but some resistance to ceftriaxone $[263,264]$. In a recent Brazilian study, Brucella species was found to be susceptible to doxycycline, streptomycin and gentamicin but high degree of resistance to rifampicin and TMP/SMZ [262]. Also, in a recent Malaysian study, high level of resistance of Brucella species to rifampicin was found [265]. As only $38 \%$ of Brucella strains are susceptible to co-trimoxazole, it is usually recommended to administer TMP/SMZ in combination with tetracycline or streptomycin [261].

Fluoroquinolones exhibit broad spectrum antibacterial activity and hence they are attractive candidates for use against infections caused by intracellular bacteria such as Brucella species due to their oral bioavailability, high tissue concentrations, evidence of intracellular penetration and in vitro activity against Brucella species [266]. Ciprofloxacin had a good promise initially, but its use as a sole agent in first line therapy has been excluded because of the following reasons: the lack of bactericidal activity against Brucella species, the development of drug resistance during therapy and the high relapse rates encountered [266]. The new generations of fluoroquinolones such as moxifloxacin, gatifloxacin, ofloxacin, grepafloxacin, trovafloxacin and sitafloxacin have shown excellent in vitro activities against B. melitensis [266]. Rifampicin is a potent broad-spectrum antibiotic and is an integral component of the combination therapy used in the treatment of human brucellosis, but it should be used with extreme caution in areas that are endemic for tuberculosis [267].

\section{Treatment considerations in immunocompromised patients}

Once the treatment of brucellosis in an immunocompromised patient is decided, the following points should be taken into consideration: (1) the same antimicrobials and therapeutic schedules can be used, but the duration of treatment may be longer, (2) interactions between antimicrobials used to treat brucellosis and cytotoxic chemotherapy or immunosuppressive therapies given to control the underlying disease should be avoided if possible, (3) in uncomplicated cases of brucellosis, simultaneous administration of antimicrobials and immunosuppressive or cytotoxic therapy may be justified, and (4) in patients having Brucella bacteremia or complicated Brucella infections, at least 2 weeks of antimicrobial therapy should be administered before subjecting the patient to cytotoxic chemotherapy or immunosuppressive treatment [95,99,107,109,114,117-119,253].

\section{Control of brucellosis}

The main components of brucellosis control and eradication strategies are: (1) elimination of the pathogen at its animal source by hygiene measures such as careful herd management and health education, (2) improving quality of the veterinary services and establishment of diagnostic laboratories that adopt international standards, (3) adoption of appropriate control and eradication programs, (4) active and continuous surveillance and identification of animals and herds at high risk, (5) vaccination of young female animals while the live-attenuated animal vaccines are contraindicated in immunocompromised humans, (6) testing and slaughtering of seropositive adult animals, (7) health education and application of strict hygiene measures to personnel in direct contact with animals, (8) coordination and cooperation between public health officials, veterinary officers and various governmental sectors such as expanded governmental, regional and international health organizations, (9) animal control with restriction of animal transportation across open borders, (10) pasteurization of milk, prompt diagnosis and appropriate treatment of infected humans, and (11) maintaining a high index of suspicion for the infection in endemic areas is of vital importance $[20,99,100,117,268-270]$.

\section{Conclusions and Future Directions}

Brucellosis is a common global re-emerging zoonosis that represents a major health and economic burden in many countries. Brucellae are Gram-negative, intracellular coccobacilli that predominantly affect organs rich in macrophages. Several species have been recognized, 6 of them are human pathogens. Infection can be acquired by: consumption of unpasteurized dairy products, direct contact with animals, blood product transfusion, sexual transmission, travel in the era of globalization and laboratory exposure. The recent immunologic, genetic and genomic advances have translated into better understanding of the pathogenesis of brucellosis and are likely to be utilized well in the vaccination, prevention and therapy of this disease.

Brucellosis has recently been increasingly recognized in immunocompromised individuals such as those with hematologic malignancy, solid tumors, HSCT, SOT, ESRD and other comorbid medical conditions. Brucellosis has rather unpredictable clinical manifestations and a variable clinical course with specific complications, hence many cases remain unrecognized. Mortality rate is less than $5 \%$ of cases and most deaths are due to complicated infections. Management of brucellosis in immunocompromised hosts requires special attention to a number of factors including the specific drugs to be used and the duration of therapy.

The diagnosis of brucellosis can provisionally be made on clinical grounds but confirmation requires certain laboratory data. The gold standard diagnostic test is the isolation of the organism from blood cultures. The lysis concentration methods and the automated cultural techniques have improved the yield rates significantly. Several serological techniques are employed in diagnosing acute, chronic and relapsing brucellosis. New diagnostic techniques such as molecular tests, genetic and immunological markers in addition to PET scans will definitely aid in the diagnosis and follow-up of patients having brucellosis, particularly immunocompromised ones living in endemic areas. 
Monotherapy may be associated with therapeutic failure and relapse, while drug combinations are usually effective. The most commonly used regimens are composed of: doxycycline combined with rifampicin and/or an aminoglycoside. The duration of treatment depends on the: duration of the illness, presence or absence of complications and primary site of infection. The new flouroquinolones, tigecycline, levamisole and IFN- $\gamma$ are likely to be incorporated into future management of brucellosis. Adverse effects of anti-Brucella therapy, interaction with immunosuppressive agents used in SOT or HSCT and the use of some medications in pregnancy are major concerns. The main components of brucellosis control programs are: animal vaccination, pasteurization of dairy products, health education of at risk populations and coordination between various governmental, regional and international organizations.

\section{References}

1. Bosilkovski M (2014) Clinical manifestations, diagnosis and treatment of brucellosis. Up To Date. Topic edited by Calderwood SB, Edwards MS and Baron EL.

2. Arizona Department of Health Services (2004) Brucellosis: Bioterrorism Agent Profiles for Health Care Workers, Office of Public Health Emergency Preparedness and Response 5.1-5.4.

3. Young EJ (1995) An overview of human brucellosis. Clin Infect Dis 21: 283289.

4. Franco MP, Mulder M, Gilman RH, Smits HL (2007) Human brucellosis. Lancet Infect Dis 7: 775-786.

5. Evans AS, Brachman PS (2009) Bacterial Infections of Humans Epidemiology and Control. (4th edition), Springer Science + Business Media, LLC, 233 New York, NY 10013, USA

6. Pappas G, Akritidis N, Bosilkovski M, Tsianos E (2005) Brucellosis. New Engl J Med 362: 2325-2336.

7. Akhvlediani T, Clark DV, Chubabria G, Zenaishvili O, Hepburn MJ (2010) The changing pattern of human brucellosis: clinical manifestations, epidemiology and treatment outcomes over three decades in Georgia. BMC Infect Dis 10 $1-9$

8. Christou $L$ (2011) The global burden of bacterial and viral zoonotic infections. Clin Microbiol Infect 17: 326-330.

9. Pappas G, Papadimitriou P, Akritidis N, Christou L, Tsianos E (2006) The new global map of human brucellosis. Lancet Infect Dis 6: 91-99.

10. Dean AS, Crump L, Greter H, Schelling E, Zinsstag J (2012) Global burden of human brucellosis: a systematic review of disease frequency. PLoS Negl Trop Dis 6: e1865.

11. Mantur BG, Amarnath SK (2008) Brucellosis in India - a review. J Biosciences 33: $539-547$

12. Seimenis A, Morelli D, Mantovani A (2006) Zoonones in the Mediterranean region. Ann Ist Super Sanità 42: 437-445.

13. Hasanjani Roushan MR, Mohraz M, Hajihamdi M, Ramzani A, Valayati AA (2006) Efficacy of gentamicin plus doxycycline versus streptomycin plus doxycycline in the treatment of brucellosis in humans. Clin Infect Dis 42 : 1075-1080.

14. Mubyazi GM, Barongo VK, Kamugisha M, Njunwa KJ (2013) Public knowledge, perceptions and practices in relation to infectious and other communicable diseases in Tanzania: lessons learnt from Babati district. Rwanda J Health Sci 2: 1-12.

15. Ariza J, Bosilkovski M, Cascio A, Colmenero JD, Corbel MJ, et al. (2007) Perspectives for the treatment of human brucellosis in the 21st Century: the loannina Recommendations. PLoS Med 4 e317.
16. Cutler SJ, Fooks AR, van der Poel WH (2010) Public health threat of new, reemerging and neglected zoonoses in the industrialized world. Emerg Infect Dis 16: 1-7.

17. Vassalo CM, Economou V, Vassalou E, Papadopaulor C (2009) Brucellosis in humans: why is it so elusive? Rev Med Microbiol 20: 63-73.

18. Gwida M, Al Dahouk S, Melzer F, Rösler U, Neubauer H, et al. (2010) Brucellosis - regionally emerging zoonotic disease? Croat Med J 51: 289-295.

19. Seleem MN, Boyle SM, Srivanganathan N (2010) Brucellosis: a re-emerging zoonosis. Veterinary Microbiol 140: 392-398.

20. Russo G, Pasquali P, Nenova R, Alexandrov T, Ralchev S, et al. (2009) Reemergence of human and animal brucellosis, Bulgaria. Emerg Infect Dis 15: 314-316

21. Farina F, Fuser R, Rossi M, Scotton PG (2008) Brucellosis outbreak in Treviso province caused by infected cheese from an endemic area. Infez Med 16: 154-157.

22. Donev D, Karadzovski A, Kasapinov B, Lazarevik V (2010) Epidemiological and public health aspects of brucellosis in the republic of Macedonia. Prilozi 31: 33-54.

23. Al-Tawfiq JA, Abukhamsin A (2009) A 24-year study of the epidemiology of human brucellosis in a health-care system in Eastern Saudi Arabia. J Infect Public Health 2: 81-85.

24. Al-Anazi KA, Al-Jasser AM (2013) Brucellosis, a global re-emerging zoonosis: history, epidemiology, microbiology, immunology and genetics. In: Bacterial and Mycotic Infections in Immunocompromised Hosts; Clinical and Microbiological Aspects. Edited by Mascellino MT. Omics eBook Group.

25. Kadanali A, Ozden K, Altoparlak U, Erturk A, Parlack M (2009) Bacteremic and nonbacteremic brucellosis: clinical and laboratory observations. Infection 37: 67-69.

26. Godfroid J, Cloeckaert A, Liautard JP, Kohler S, Fretin D, et al. (2005) From the discovery of Malta fever's agent to the discovery of a marine mammal reservoir, brucellosis has continuously been a re-emerging zoonosis. Vet Res 36: 313-326.

27. Economidou J, Kalafatas P, Vatopoulou T, Petropoulou D, Kattamis C (1976) Brucellosis in two thalassaemic patients infected by blood transfusions from the same donor. Acta Haematol 55: 244-249

28. Akcakus M, Esel D, Cetin N, Kisaarslan AP, Kurtoglu S (2005) Brucella melitensis in blood cultures in two newborns due to exchange transfusion. Turkish J Pediatr 47: 272-274

29. Ertem M, Kürekci AE, Aysev D, Unal E, Ikinciogullari A (2005) Brucellosis transmitted by bone marrow transplantation. Bone Marrow Transplant 26: 225-226.

30. Meltzer E, Sidi Y, Smolen G, Banai M, Bardenstein S, et al. (2010) Sexually transmitted brucellosis in humans. Clin Infect Dis 51: e12-15.

31. Vandercam B, Zech F, de Cooman S, Bughin C, Gigi J, et al. (1990) Isolation of Brucella melitensis from human semen. Eur J Clin Microbiol Infect Dis 9 : 303-304.

32. Khorasgani MR, Esmaeili H, Pourkarim MR, Mankhian AR, Salehi TZ (2008) Anti-Brucella antibodies in blood donors in Boushehr, Iran. Comp Clin Patho 17: 267-269.

33. Nomura A, Imaoka K, Imanishi H, Shimizu H, Nagura F, et al. (2010) Human Brucella canis infections diagnosed by blood culture. Emerg Infect Dis 16: 1183-1185

34. Bonfah B, Kasymbekov J, Dürr S, Toktobaev N, Doherr MG, et al. (2012) Representative seroprevalences of brucellosis in humans and livestock in Kyrgyzstan. EcoHealth 9: 132-138.

35. Zolzaya B, Selenge T, Narangarav T, Gantsetseg D, Erdenechimeg D, et al (2014) Representative seroprevalences of brucellosis humans and livestock in two Mongolian provinces. EcoHealth 11: 356-371. 
36. Ali S, Ali Q, Neubauer H, Melzer F, Elschner M, et al. (2013) Seroprevalence and risk factors associated with brucellosis as a professional hazard in Pakistan. Foodborne Pathog Dis 10: 500-505.

37. Islam MA, Khatun MM, Were SR, Sriranganathan N, Boyle SM (2013) A review of Brucella seroprevalence among humans and animals in Banladesh with special emphasis on epidemiology, risk factors and control opportunities. Vet Microbiol 166: 317-326.

38. Khan MY, Mah MW, Memish ZA (2001) Brucellosis in pregnant women. Clin Infect Dis 32: 1172-1177.

39. Aworh MK, Okolocha E, Kwaga J, Fasina F, Lazarus D, et al. (2013) Human brucellosis: seroprevalence and associated exposure factors among abattoi workers in Abuja, Nigeria-2011. Pan Afr Med J 16: 103

40. Narayan S (2001) Microbes and blood transfusion. Indian J Med Microbiol 19: 119-126.

41. Wang W, Liao Q, Wu X, Hou S, Wang Y, et al. (2015) Potential risk of blood transfusion-transmitted brucellosis in an endemic area in China. Transfusion 55: 586-592.

42. Yavuz MT, Kaya D, Behcet M, Aksit H (2012) Detection of Brucella among voluntary blood donors in Turkey using a new real time PCR method. J Anim Vet Advances 11: 3247-3250.

43. He Y (2012) Analyses of Brucella pathogenesis, host immunity and vaccine targets using systems biology and bioinformatics. Front Cell Infect Microbiol

44. Atluri VL, Xavier MN, de Jong MF, den Hartigh AB, Tsolis RM (2011) Interactions of the human pathogenic Brucella species with their hosts. Annu Rev Microbiol 65: 523-541.

45. Baldwin CL, Goenka R (2006) Host immune responses to the intracellula bacteria Brucella: Does the bacteria instruct the host to facilitate chronic infection? Crit Rev Immunol 26: 407-442.

46. Bosilkovski M (2014) Microbiology, epidemiology and pathogenesis of brucellosis. Topic edited by Calderwood SB, Edwards MS, Baron EL. Up To Date. Topic last updated 02, 2014.

47. Elfaki MG, Al-Hokail AA, Kambal AM (2012) Microbial immunosuppression. Immunosuppression-Role in Health and Disease. Edited by Kapur S. ISBN 978-953-51-0152-9. In Tech 215-224.

48. Ritchie JA, Rupper A, Cardelli JA, Bellaire BH (2012) Host interferon- $\gamma$ inducible protein contributes to Brucella survival. Front Cell Infect Microbiol 2 $1-11$.

49. Supriya C, Umapathy BL, Ravikumar KL (2010) Brucellosis: review on the recent trends in pathogenicity and laboratory diagnosis. J Lab Physicians 2 : $55-60$

50. Asaei S, Rasouli M, Moravej A (2013) Interleukin-8 but not interleukin-6 variant may affect susceptibility to brucellosis. Iran J Immunol 10: 158-166.

51. Eskandari-Nasab E, Moghadampour M, Asadi-Saghandi A, Kharazi-nejad E, Rezaeifar A, et al. (2013) Levels of interleukin-(IL)-12p40 are markedly increased in brucellosis among patients with specific IL-12B genotype. Scand J Immunol 78: 85-91.

52. Olt S, Ergenç H, Açikgöz SB (2015) Predictive contribution of neutrophil/ lymphocyte ratio in diagnosis of brucellosis. BioMed Res Int 2015 (210502): $1-4$

53. Martirosyan A, Moreno E, Gorvel JP (2011) An evolutionary strategy for a stealthy intraceullar Brucella pathogen. Immunol Rev 240: 211-234.

54. Backert S, Meyer TF (2006) Type IV secretion systems and their effectors in bacterial pathogenesis. Curr Opin Microbiol 9: 207-217.

55. Rolán HG, den Hartigh AB, Kahl-McDonagh M, Ficht T, Adams LG, et al (2008) VirB12 is a serological marker of Brucella infection in experimental and natural hosts. Clin Vaccine Immunol 15: 208-214.

56. Hanna N, Jiménez de Bagüés MP, Ouahrani-Bettache S, El Yakhlifi Z, et al. (2011) The virB operon is essential for lethality of Brucella microti in the
Balb/c murine model of infection.. J Infect Dis 203: 1129-1135.

57. Al-Anazi KA, Al-Jasser AM (2013) Brucellosis, a global re-emerging zoonosis: clinical aspects, associations and brucellosis in specific conditions In: Bacterial and Mycotic Infections in Immunocompromised Hosts; Clinical and Microbiological Aspects. Edited by Mascellino MT. Omics eBook Group.

58. Buzgan T, Karahocagil MK, Irmak H, Baran Al, Karsen H, et al. (2010) Clinical manifestations and complications in 1028 cases of brucellosis: a retrospective evaluation and review of the literature. Int J Infect Dis 14: e 469-478.

59. Demiroglu YZ, Turunc T, Aliskan H, Colakoglu S, Arslan H (2007) Brucellosis: retrospective evaluation of the clinical, laboratory and epidemiological features of 151 cases. Mikrobiyol Bul 41: 517-527.

60. Lulu AR, Araj GF, Khateeb MI, Mustafa MY, Yusuf AR, et al. (1988) Human brucellosis in Kuwait: a prospective study of 400 cases. Quart J Med 66: 39 54

61. Sari I, Altuntas F, Hacioglu S, Kocyigit I, Sevinc A, et al. (2008) A multicenter retrospective study defining the clinical and hematological manifestations of brucellosis and pancytopenia in a large series: Hematological malignancies, the unusual cause of pancytopenia in patients with brucellosis. Am J Hematol 83: 334-339.

62. Norton WL (1984) Brucellosis and rheumatic syndromes in Saudi Arabia. Ann Rheum Dis 43: 810-815.

63. Araj GF (2010) Update on laboratory diagnosis of human brucellosis. Int J Antimicrob Agents 36: S12-S17.

64. Pandit VR, Seshadri S, Valsalan R, Bahuleyan S, vandana KE, et al. (2010) Acute brucellosis complicated by fatal myocarditis. Int J Infect Dis 14 e358-e360

65. Gatselis NK, Makaritsis KP, Gabranis I, Stefos A, Karanikas K, et al. (2011) Unusual cardiovascular complications of brucellosis presenting in two men: two case reports and a review of the literature. J Med Case Rep 5: 22.

66. Kaya S, Eskazan AE, Elaldi N (2013) Brucellar pericarditis: a report of four cases and review of the literature. Int J Infect Dis 17: e428-432.

67. García de Lucas MD, Castillo Domínguez JC, Martínez González MS (2004) Brucella myopericarditis. Rev Esp Cardiol 57: 709.

68. Gunes Y, Tuncer M, Guntekin U, Akdag S, Ali Gumrukcuoglu H, et al. (2009) Clinical characteristics and outcome of Brucella endocarditis. Trop Doct 39: 85-88.

69. Efe C, Can T, Ince M, Tunca H, Yildiz F, et al. (2009) A rare complication of Brucella infection: myocarditis and heart failure. Intern Med 48: 1773-1774.

70. Andriopoulos P, Antoniou C, Manolakou P, Vasilopoulos A, Assimakopoulos $\mathrm{G}$, et al. (2015) Brucella endocarditis as a late onset complication of brucellosis. Case Rep Infect Dis 2015: 836826.

71. Zisis C, Argyriou M, Kokotsakis I, Boutsikakis I, Lolas C (2002) Brucella Endocarditis, presentation of two cases and literature review. Hellenic $J$ Cardiol 43: 174-177.

72. Cay S, Cagirci G, Maden O, Balbay Y, Aydogdu S (2009) Brucella endocarditis - a registry study. Kardiol Pol 67: 274-280.

73. Abid L, Frikha Z, Kallel S, Chokri Z, Ismahen B, et al. (2012) Brucella myocarditis: a rare and life-threatening cardiac complication of brucellosis. Intern Med 51: 901-904

74. Abbasi F, korooni S (2015) Neurobrucellosis In: Updates on brucellosis. Edited by Boddour MM. InTech. ISBN 978-953-51-2211-1.

75. Gul HC, Erdem H, Gorenek L, Ozdag MF, Kalpakci Y, et al. (2008) Management of neurobrucellosis: an assessment of 11 cases. Intern Med 47 995-1001.

76. Gul HC, Erdem H, Bek S (2009) Overview of neurobrucellosis: a pooled analysis of 187 cases. Int $\mathrm{J}$ Infect Dis 13: e339-343.

77. Yetkin MA, Bulut C, Erdinc FS, Oral B, Tulek N (2006) Evaluation of the clinical presentations in neurobrucellosis. Int J Infect Dis 10: 446-452. 
78. Ceran N, Turkoglu R, Erdem I, Inan A, Engin D, et al. (2011) Neurobrucellosis: clinical, diagnostic, therapeutic features and outcome. Unusual clinica presentations in an endemic region. Braz J Infect Dis 15: 52-59.

79. Park KW, Kim DM, Park CY, Kim HL, Jang SJ, et al. (2007) Fatal systemic infection with multifocal liver and lung nodules caused by Brucella abortus. Am J Trop Med Hyg 77: 1120-1123.

80. Kaya O, Avşar K, Zeynep Akçam F (2011) Unusual manifestations of brucellosis. Arch Med Sci 7: 173-175.

81. Starakis I, Polyzogopoulou E, Siagris D, Mazokopakis E, Gogos CA (2008) Unusual manifestations of brucellosis: liver abscess and pancytopenia caused by Brucella melitensis. Eur J Gastroenterol Hepatol 20: 349-352.

82. Haran M, Argawal A, Kipfer Y, Seneviratne C, Chawla K, et al. (2011) Brucellosis presenting as septic shock. BMJ Case Rep 2011pii: bcr1220103586.

83. Naz H, Aykin N, Cevik F, Bal C (2009) Brucellosis in central Anatolia: evaluation of complications and relapse. Trop Doct 39: 107-109.

84. Alavi SM, Alavi SMR, Alavi L. (2009) Relapsed human brucellosis and related risk factors. Pak J Med Sci 25: 46-50.

85. Ariza J, Corredoira J, Pallares R, Viladrich PF, Rufi G, et al. (1995) Characteristics of and risk factors for relapse of brucellosis in humans. Clin Infect Dis 20: 1241- 1249 .

86. Ibarra V, Blanco JR, Metola L, Oteo JA (2003) Relapsing brucellosis in a patient with human immunodeficiency virus (HIV). Clin Microbiol Infect 9 : 1259-1260.

87. (1974) Editorial: Chronic brucellosis. Br Med J 1: 299.

88. McDevitt MG (1973) Symptomatology of chronic brucellosis. Br J Ind Med 30: 385-389.

89. White RG (1978) Immunoglobulin profiles of the chronic antibody response: discussion in relation to brucellosis infections. Postgrad Med J 54: 595-602.

90. Castaño Aroca MJ, Garcia EN, J.S. Santos JS (2011) Association between Brucella melitensis DNA and Brucella spp. antibodies. Clin Vaccine Immuno 18: 892

91. Castaño MJ, Solera J (2009) Chronic brucellosis and persistence of Brucella melitensis DNA. J Clin Microbiol 47: 2084-2089.

92. Nimri LF (2003) Diagnosis of recent and relapsed cases of human brucellosis by PCR assay. BMC Infect Dis 3: 5 .

93. Meneses A, Epaulard O, Maurin M, Gressin R, Pavese P, et al. (2010) Brucella bacteremia reactivation 70 years after the primary infection. Med Mal Infect 40: 238-240.

94. Ögredici Ö, Erb S, Langer I, Pilo P, Kerner A, et al. (2010) Brucellosis reactivation after 28 years. Emerg Infect Dis 16: 2021- 2022.

95. Behnava B, Keshvari M, Miri SM, Elizee PK, Alavian SM (2011) Reactivation of brucellosis during pegylated interferon-alpha therapy in a thalassemic patient with chronic hepatitis C. Exper Clin Hepatol 7: 57-59.

96. Mutolo MJ, Jenny LL, Buszek AR, Fenton TW, Foran DR (2012) Osteological and molecular identification of brucellosis in ancient Butrint, Albania. Am J Phys Anthropol 147: 254-263.

97. Isidro A, Etxeberria F, Roca C, Guijo M, Malgosa A. (2009) Old skeleta brucellosis in Western-Europe Mediterranean countries. J Bone Joint (previously called J Bone Joint Surg Br) 91-B (Supp II) 299.

98. Kay GL, Sergeant MJ, Giuffra V, Bandiera P, Milanese M, et al. (2014) Recovery of medieval Brucella melitensis genome using shotgun metagenomics. MBio 5: e01337-14

99. Al-Anazi KA, Al-Jasser AM (2007) Brucella bacteremia in patients with acute leukemia: a case series. J Med Case Rep 1: 144

100.Al-Anazi KA, Abu Jafar S, Al-Jasser AM, Al-Omar H, Al-Mohareb FI (2009) Brucella bacteremia in a recipient of an allogeneic hematopoietic stem cell transplant: a case report. Cases J 2: 91.
101. Nicolson GL, Haier J (2010) Role of chronic bacterial and viral infections in neurodegenerative, neurobehavioural, psychiatric, autoimmune and fatiguing illnesses: part 2. Br J Med Pract 2: 301-310.

102. Spicknail CG, Kurland LT, Carle BN, Terry LL (1950) Relation of brucellosis and multiple sclerosis. J Am Med Assoc 143: 1470-1473.

103.Zhang B, Izadjoo M, Horkayne-Szakaly I, Morrison A, Wear DJ (2011) Medulloblastoma and brucellosis-molecular evidence of Brucella sp. in association with central nervous system cancer. J Cancer 2: 136-141.

104.Chan KM, Lee WC (2012) Donor-derived infectious complications and disease transmission. In: Liver transplantation-technical issues and complications. Edited by Abdeldayem H. In-Tech ISBN: 978-953-51-0015-7.

105. Francio-Paredes C, Jacob JT, Hidron A, Rodriguez-Morales AF, Kuhar D, et al. (2010) Transplantation and tropical infectious diseases. Int J Infect Dis 114: e189-e196.

106. Li JJ, Sheng ZK, Tu S, Bi S, Shen XM, et al. (2012) Acute brucellosis with myelodysplastic syndrome presenting as pancytopenia and fever of unknown origin. Med Princ Pract 21: 183-185.

107. Cokca F, Yilmaz-Bozkurt G, Azap A, Memikoglu O, Tekeli E (2006) Meningoencephalitis, pancytopenia, pulmonary insufficiency and splenic abscess in a patient with brucellosis. Saudi Med J 27: 539-541.

108. López L, del Villar V, Bergua J (1995) Fever caused by myeloma or brucellosis? Overlapping of 2 entities. Sangre (Barc) 40: 165-166.

109. Kang KU, Jung YS, Park KH, Jung SI, Shin JH, et al. (2008) A case of Brucella endocarditis with spondylitis in a patient with multiple myeloma. Korean J Med 74: 561-565

110. Akkoyunlu ME, Akkoyunlu Y, Hakyemez IN, Erboy F, Arvas G, et al. (2013) Lung cancer, brucellosis and tuberculosis; remarkable togetherness. Asian Pac J Trop Dis 3: 327-330.

111. Karabakan M, Akdemir S, Akdemir AO, Erkmen AF, Kayabas U (2014) A rare case of prostatic brucellosis mimicking prostatic cancer. Urology $\mathrm{J} 11$ : 1987-1988.

112. Parsa N, Almasi-Hashiani A (2012) Brucella bacterium induces infection and human cancers: review article. Arak Med Univer J 14: 95-99.

113. Fishman JA, Grossi PA (2014) Donor-derived infection - the challenge for transplant safety. Nature Rev Nephrol 10: 663-672.

114. Fishman JA (2014) Infection in solid organ transplant recipient. Edited by Marr KA, Thorne AR. Up To Date

115. Fischer SA, Avery RK and the AST Infectious Disease Community of Practice. (2009) Screening of donor and recipient prior to solid organ transplantation. Am J Transplant 9: S7-S18.

116. Niederwieser D, Gentilini C, Hegenbart U, Lange T, Moosmann P, et al (2004) Transmission of donor illness by stem cell transplantation: should screening be different in older donors? Bone Marrow Transplant 34: 657665

117. Kotton CN (2007) Zoonoses in solid-organ and hematopoietic stem cell transplant recipients. Clin Infect Dis 44: 857-866.

118. Yesilkaya A, Azap K, Arslan H, Özalp O, Kirnap M (2013) Infection in the immunocompromised host and transplant recipients: Brucellosis in solid organ transplantation. 23rd Europian Society of Clinical Microbiology and Infectious Diseases Congress; 27-30 April 2013; Berlin, Germany.

119. Islek A, Sayar E, Yilmaz A, Günseren F, Artan R (2013) Relapsing brucellosis after liver transplantation in a child: what is the appropriate regimen and duration of therapy? Transplantation 96: e 6-7.

120. Yousif B, Nelson J (2001) Neurobrucellosis--a rare complication of renal transplantation. Am J Nephrol 21: 66-68.

121. Einollahi B, Hamedanizadeh AK, Alavian SM (2003) Brucellosis arthritis--a rare complication of renal transplantation: a case report. Transplant Proc 35: 2698. 
122. Bishara J, Robenshtok E, Weinberger M, Yeshurun M, Sagie A, et al. (1999) Infective endocarditis in renal transplant recipients. Transpl Infect Dis 1: 138 143.

123. Ting IW, Ho MW, Sung YJ, Tien N, Chi CY, et al. (2013) Brucellosis in a renal transplant recipient. Transpl Infect Dis 15: E191-195.

124.Bihl F, Castelli D, Marincola F, Dodd RY, Brander C (2007) Transfusiontransmitted infections. J Transl Med 5: 25

125. Machado CM, Levi JE (2012) Transplant-associated and blood transfusionassociated tropical and parasitic infections. Infect Dis Clin North Am 26: 225 241.

126. Naparstek E, Block CS, Slavin S (1982) Transmission of brucellosis by bone marrow transplantation. Lancet 1: 574-575.

127.Larghero J, Garcia J, Gluckman E and the Europian Group for Blood and Marrow Transplantation. (2008) Sources and procurement of stem cells. In: Hematopoietic Stem Cell Transplantation. The EBMT Handbook; Revised Edition, 112-127. Edited by: Apperley J, Carreras E, Gluckman E, Gratwhol A, Masszi T.

128. Erkurt MA, Berber I, Kuku I, Kaya E, Nizam I (2014) Donor selection in allogeneic stem cell transplantation. Am J Clin Med Res 2: 32-35

129. Mohammad KI, El Ghazaly MM, Zaalouk TK, Morsy AT (2011) Maternal brucellosis and human pregnancy. J Egypt Soc Parasitol 41: 485-496.

130. Kurdoglu M, Adali E, Kurdoglu Z, Karahocagil MK, Kolusari A, et al. (2010) Brucellosis in pregnancy: a 6-year clinical analysis. Arch Gynecol Obste 281: 201- 206

131. Schreyer P, Caspi E, Leiba Y, Eshchar Y, Simpolinski D (1980) Brucella septicemia in pregnancy. Eur J Obstet Gynecol Reprod Biol 10: 99-107.

132. Gloeb DJ, Lupi C, O'Sullivan MJ (1994) Neurobrucellosis complicating pregnancy: a case report. Infect Dis Obstet Gynecol 1: 285-289.

133. Gulsun S, Aslan S, Satici O, Gul T (2011) Brucellosis in pregnancy. Trop Doct 41: 82-84.

134. Roushan MR, Baiani M, Asnafi N, Saedi F (2011) Outcome of 19 pregnan women with brucellosis in Babol, northern Iran. Trans R Soc Trop Med Hyg 105: $540-542$

135. Hackmon R, Bar-David J, Bashiri A, Mazor M (1998) Brucellosis in pregnancy. Harefuah 135: 3-7.

136. Elshami M, Ahmed Al (2008) The effects of maternal brucellosis on pregnancy outcome. J Infect Dev Ctries 2: 230-234

137. Nuri P, Volkan T, Mete E, Ozgur $Y$ (2011) Brucellosis in adolescent pregnancy-case report and review of literature. Ginekol Pol 82: 226-229.

138. Karcaaltincaba D, Senan I, Kandemir O, Guvendag-Guven ES, Yalvac S (2010) Does brucellosis in human pregnancy increase abortion risk? Presentation of two cases and review of literature. J Obstet Gynaecol Res 36: 418-423.

139. Makhseed M, Harouny A, Araj G, Moussa MA, Sharma P (1998) Obstetric and gynecologic implications of brucellosis in Kuwait. J Perinatol 18: 196199.

140. Al-Tawfiq JA, Memish ZA (2013) Pregnancy associated brucellosis. Recent Pat Antiinfect Drug Discov 8: 47-50.

141. Abo-Shehada MN, Abu-Halaweh M (2011) Seroprevalence of Brucella species among women with miscarriage in Jordan. East Mediterr Health $J$ 17: 871-874.

142. Nassaji M, Rahbar N, Ghorbani R, Lavaf S (2008) The role of Brucella infection among women with spontaneous abortion in an endemic region. J Turk Ger Gynecol Assoc 9: 20-23.

143. Sharif A, Reyes Z, Thomassen P (1990) Screening for brucellosis in pregnant women. J Trop Med Hyg 93: 42-43.

144. Figueroa Damian R, Rojas Rodríguez L, Marcano Tochon ES (1995) Brucellosis in pregnancy: course and perinatal results. Ginecol Obstet Mex
63: 190-195.

145. Al-Amoudi SM (1995) Brucellosis in pregnancy in Bisha, Saudi Arabia. Saud Med J 16: 315-318.

146. Bakri FG, Al-Bsoul NM, Magableh AY, Shehabi A, Tarawneh M, et al. (2010) Brucellosis presenting as myelofibrosis: first case report. Int $\mathrm{J}$ Infect Dis 14: e158-e160.

147. Tyagi A, Verma T, Argawal S, Gupta RM (2014) Brucellosis as a cause of neutropenia in acute myeloid leukemia: a case report. Sch. J. App. Med. Sc 2: $1618-1620$

148. Ozbalci D, Ergene U, Cetin CB (2011) Brucellosis: a rare cause of febrile neutropenia in acute myeloblastic leukemia. Med Oncol 28: 255-257.

149. Ozçay F, Derbent M, Ergin F, Ozbek N (2000) Febrile neutropenia caused by Brucella melitensis in a child with hypoplastic acute lymphoblastic leukemia. Med Pediatr Oncol 35: 496-497.

150. Bay A, Oner AF, Dogan M, Acikgoz M, I. Dilek I (2007) Brucellosis concomitant with acute leukemia. Indian J Pediatr 74: 790-792.

151. Eser B, Altuntas F, Soyuer I, Ozlem Er, Ozlem Canoz, et al. (2006) Acute lymphoblastic leukemia associated with brucellosis in two patients with fever and pancytopenia. Yonsei Med J 47: 741-744.

152. Solmaz S, Asma S, Ozdoğu H, Yeral M, Turunc T (2014) An unusual cause of febrile neutropenia: brucellosis. Mikrobiyol Bul 48: 669-673.

153. Sari R, Buyukberber N, Sevnic A, Bayindir Y, Buyukberber S (2002) Brucellosis in the etiology of febrile neutropenia: case report. J Chemother 14: 88-91.

154. Citak EC, Arman D (2011) Brucella melitensis: a rare cause of febrile neutropenia. Pediatr Hematol Oncol 28: 83-85.

155. Metan G, Sardan YC, Hascelik G (2006) Brucellosis in all patients with febrile neutropenia. Leuk Lymphoma 47: 954-956.

156. Arda B, Tasbakan MI, Pullukcu H, Sipahi OR, Aydemir S, et al. (2007) Brucella melitensis in the etiology of febrile neutropenia: report of two cases brucellosis and febrile neutropenia. Int J Clin Pract 61: 1237-1238.

157. Turunç T, Demiroğlu YZ, Alişkan H, Colakoğlu S, Timurkaynak $F$, et al (2008) Brucellosis in cases of end-stage renal disease. Nephrol Dial Transplant 23: 2344-2349.

158. Kantartzi K, Panagoutsos S, Kokkinou V, Passadakis P, Vargemezis V (2009) Unexpectedly high incidence of brucellosis in one university dialysis unit of North East Greece. Nephrol Dial Transplant 24: 2003-2004.

159. Ghanei E, Miladipour A, Nasrollahi A, Homayuni M (2009) Brucellosis with kidney failure. Iran J Kidney Dis 3: 109-111.

160. Karp CL, Auwaerter PG (2007) Coinfection with HIV and tropical infectious diseases. II. Helminthic, fungal, bacterial and fungal pathogens. Edited by Mayers KH. Clin Infect Dis 45: 1214-1220.

161. Lawaczeck E, Toporek J, Cwikla J, Mathison BA (2011) Brucella canis in a HIV-infected patient. Zoonoses Public Health 58:150-152.

162. Hajiabdolbaghi M, Rasoulinejad M, Abdollahi A, Paydary K, Valiollahi P, et al. (2011) Brucella infection in HIV infected patients. Acta Med Iran 49: $801-$ 805.

163. Moreno S, Ariza J, Espinosa FJ, Podzamczer D, Miró JM, et al. (1998) Brucellosis in patients with the Human Immunodeficiency Virus. Eur J Clin Microbiol Infect Dis 17: 319-326.

164. Lucero NE, Maldonado PI, Kaufman S, Escobar GI, Boeri E, et al. (2010) Brucella canis causing infection in an HIV-infected patient. Vector Borne Zoonotic Dis 10: 527-529.

165. Abdollahi A, Morteza A, Khlilzadeh O, Rasoulinejad M (2010) Brucellosis serology in HIV-infected patients. Int J Infect Dis 14: e904-e906.

166. Kurtaran B, Oto OA, Candevir A, Inal AS and Y. Sirin Y (2011) A case of HIV infection with thrombocytopenia: association of HIV, thrombotic thrombocytopenic purpura and brucellosis. Indian J Hematol Blood Transfus 


$$
\text { 27: } 35-38 .
$$

167.Fakhar M, Banimustafavi E, Motazedian MM, Asgari Q (2009) Co-infection of Leishmania infantum and Brucella spp. in Iran. Comp Clin Pathol 18: 9394.

168. Abou EIAzm AR, Abou-Ali L, Kobtan AR, Mansour N, Tawfik S (2013) Can brucellosis influence the course of hepatitis $C$ in dual infection? Arch Virol 158: $543-547$

169. Cocchi S, Bisi L, Codeluppi M, Venturelli C, Di Benedetto F, et al. (2010) Brucellosis in a patient with end-stage liver disease undergoing liver transplantation: successful treatment with tigecycline. Liver Transplant 16: 1215-1216.

170.Bzeizi KI, Benmousa A, Sanai FM (2010) Coincidence of acute Brucella hepatitis and dengue fever or serologic cross-reactivity? Saudi J Gastroenterol 16: 299-301.

171. Ayyub M, Al-Juhani NR, Alfi AY, Al-Ukayli S. (2006) Brucellosis and dengue fever - a co-infection or cross reactivity? Biomedica 22: 80-83.

172. Jacob NR, Rodríguez CG, Binaghi MA, Scapellato PG, Rosales Ostriz $\mathrm{MB}$, et al. (2008) Brucellosis complicating chronic non-infectious disorders: diagnostic and therapeutic dilemmas. J Med Microbiol 57: 1161-1166.

173. Akgul O, Ozgocmen S (2011) Infliximab and brucellosis: not the usual suspects, this time. Mod Rheumatol 21: 313-315.

174. Eisele CW, McCullough NB, Beal GA (1950) Brucellosis and multiple sclerosis. J Am Med Assoc 143: 1473-1474.

175. Murrell TG, Mathews BJ (1990) Multiple sclerosis -- one manifestation of neurobrucellosis? Med Hypotheses 33: 43-48.

176. Emara MM, Vyas V, al Awadi S, Jaroslav N, el Khodry A, et al. (2007) Synchronous occurrence of brucellosis and ovarian cancer - a case report. Austral-Asian J Cancer 6: 257-259.

177. Barutca S, Sivri B (1998) Brucellosis and hepatocellular carcinoma: just a coincidence? Am J Gastroenterol 93: 854-855.

178. Celen MK, Ulug M, Ayaz C, Geyik MF, Hosoglu S (2010) Brucella epididymoorchitis in southeastern part of Turkey: an 8 year experience. Brazil J Infect Dis 14: 109-115.

179. Turhan V, Acar A, Ates F, Diktas H, Haholu A, et al. (2013) Orchiectomy performed in two patients with brucellar orchitis mimicking testicular tumor. West Indian Med J 62: 557-560.

180. Kocak I, Dündar M, Culhaci N, Unsal A (2004) Relapse of brucellosis simulating testis tumor. Int J Urol 11: 683-685.

181. Guy M, Nissim F, Eisenkraft S, Eliraz A (1992) Brucella infection of the testis mimicking malignancy. Harefuah 123: 260-262.

182. Probst $P$, Karrer U, Flury-Frei R, John H, Horstmann M (2011) Brucellosis as a differential diagnosis of cancer of the testes. Urologe A. 50: 71-73.

183. Memish ZA, Venkatesh S (2001) Brucella epididymo-orchitis in Saudi Arabia: a retrospective study of 26 cases and review of the literature. BJU Int 88: 72-76

184. Papatsoris AG, Mpadra FA, Karamouzis MV, Frangides CY (2002) Endemic brucellar epididymo-orchitis: a 10-year experience. Int J Infect Dis 6: 309 313.

185. Greenberg SB (2002) Infections in the immunocompromised rheumatologic patient. Crit Care Clin 18: 931-956.

186. Papagoras CE, Argyropoulou MI, Voulgari PV, Vrabie I, Zikou AK, et al. (2009) A case of Brucella spondylitis in a patient with psoriatic arthritis receiving infliximab. Clin Exper Rheumatol 27: 124-127.

187. Jimenez FG, Colmenero JD, Irigoyen MV (2005) Reactivation of brucellosis after treatment with infliximab in a patient with rheumatoid arthritis. J Infect 50: $370-371$.

188. AIDahouk S, Sprague LD, Neubauer H (2013) New developments in the diagnostic procedures for zoonotic brucellosis in humans. Rev Sci Tech $32: 177-188$

189. Coates TD (2014) Infectious causes of neutropenia. Edited by Boxer LA Tirnauer JS. Up To Date. Topic last updated: June 16, 2014.

190. Madkour MM (2001) Haematological localization. In: Madkour's Brucellosis Second edition; Springer; Chapter 4: 33-38.

191. Young EJ, Tarry A, Genta RM, Ayden A, Gutuzzo E (2000) Thrombocytopenic purpura associated with brucellosis: report of 2 cases and literature review. Clin Infect Dis 31: 904-909.

192. Sevinc A, Buyukberber N, Camci C, Buyukberber S, Karsligil T (2005) Thrombocytopenia in brucellosis: case report and literature review. J Nat Med Assoc 97: 290-293.

193. Jahromi MK, Javadzadeh T, Jodayri DS, Talaie R, Kazemi A (2006) A 40 years old woman with fever and pancytopenia. Iran J Clin Infect Dis 1: 39-41.

194. Akdeniz H, Irmak H, Seckinli T, Buzgan T, Demiröz AP (1998) Hematological manifestations in brucellosis cases in Turkey. Acta Med Okayama 52: 63-65.

195. Dilek I, Durmus A, Karahocagil MK, Akdeniz H, Karsen H, et al. (2008) Hematological complications in 787 cases of acute brucellosis in Eastern Turkey. Turkish J Med Sci 38: 421-424.

196. Abdi-Liae Z, Soudbakhsh S, Jafari S, Emadi H, Tomaj K (2007) Haematological manifestations of brucellosis. Acta Med Iran 45: 145-148.

197. Crosby E, Liosa L, Miro Quesada M, Carrillo C, Gotuzzo E (1984) Hematological changes in brucellosis. J Infect Dis 150: 419-424.

198. Sari I, Kocyigit I, Altuntas f, Kaynar L, Eser B. (2008) An unusual case of acute brucellosis presenting with Coombs-positive autoimmune hemolytic anemia. Intern Med 47: 1043-1045.

199. Martin-Moreno S, Soto-Guzman O, Bernaldo-de-Quirōs J, Reverte-Cejudo D, Bascones-Casas C (1983) Pancytopenia due to hemophagocytosis in patients with brucellosis: a report of four cases. J Infect Dis 147: 445-449.

200. Kuperman AA, Baidousi A, Nasser M, Braester A, Nassar F (2010) Microangiopathic anemia of acute brucellosis-is it a true TTP? Mediterr J Hematol Infect Dis 2: ĕ 2010031.

201. Altuntas F, Eser B, Sari I, Yildiz O, Cetin M, Ünal A (2005) Severe thrombotic microangiopathy associated with brucellosis: successful treatment with plasmapheresis. Clin Appl Thromb Hemost 11: 105-108.

202. Erdem F, Kiki I, Gundogdu M, Kaya H (2007) Thrombotic thrombocytopenic purpura in a patient with Brucella infection is highly responsive to combined plasma infusion and antimicrobial therapy. Med Princ Pract 16: 324-326.

203. Di Mario A, Sica S, Zini G, Salutari P, Leone G. (1995) Microagiopathic hemolytic anemia and severe thrombocytopenia in Brucella infection. Ann Hematol 70: 59-60.

204. Erkurt MA, Sari I, Gul HC, Coskun O, Eyigün CP, et al. (2008) The first documented case of brucellosis manifested with pancytopenia and capillary leak syndrome. Intern Med 47: 863-865

205. Jha A, Adhikari RC, Sarda R (2012) Bone marrow evaluation in patients with fever of unknown origin. J Pathol Nepal 2: 231-240.

206. Hasserjian RP (2010) Infectious diseases of the bone marrow and spleen. In: Diagnostic Pathology of Infectious Disease. Edited by Kradin RL. ISBN: 978-1-4160-3429-2. Elsevier: 325-340.

207. Deepak S, Bronson SG, Sibi, Joseph W, Thomas M (2003) Brucella isolated from bone marrow. J Assoc Physicians India 51: 717-718.

208. Gotuzzo E, Carrillo C, Guerra J, Llosa L (1986) An evaluation of diagnostic methods for brucellosis-the value of bone marrow. J Infect Dis 53: 122-125.

209. Yagupsky P (1999) Detection of Brucellae in blood cultures. J Clin Microbiol 37: $3437-3442$

210. Işeri S, Bulut C, Yetkin MA, Kinikli S, Demiröz AP, Tülek N (2006) Comparison of the diagnostic value of blood and bone marrow cultures in brucellosis. Mikrobiyol Bul 40: 201-206. 
211. Ruiz J, Lorente I, Perez J, Simarro E, Martinez-Campos L (1997) Diagnosis of brucellosis by using blood cultures. J Clin Microbiol 35: 2417-2418.

212. Duong S, Dezube BJ, Desai G, Eichelberger K, Qian Q, et al. (2009) Limited utility of bone marrow culture: a ten-year retrospective analysis. LabMedicine 40: $37-38$

213. Mantur BG, Mulimani MS, Bidari LH, Akki AS, Tikare NY (2008) Bacteremia is as unpredictable as clinical manifestations in human brucellosis. Int $J$ Infect Dis 12: 303-307.

214. Yagupsky P (2004) Use of the BACTEC MYCO/F LYTIC medium for detection of Brucella melitensis bacteremia. J Clin Microbiol 42: 2207-2208.

215. Espinosa BJ, Chacaltana J, Mulder M, Franco MP, Blazes DL, et al. (2009) Comparison of culture techniques at different stages of brucellosis. Am J Trop Med Hyg 80: 625-627.

216. Arabestani MR, Rastiany S, Kazemi S, Mousavi SM (2015) Conventional molecular methods and biomarkers molecules in detection of septicemia. Adv Biomed Res 4: 120

217. Al-Anazi KA, Al-Jasser AM (2013) Brucellosis; a global re-emerging zoonosis diagnosis, treatment and prevention. In: Bacterial and mycotic infections in immunocompromised hosts; clinical and microbiological aspects. Edited by Mascellino MT. Omics eBook Group.

218. Pabuccuoglu O, Ecemis T, El S, Coskun A, Akcali S, Sanlidag T (2011) Evaluation of serological tests for diagnosis of brucellosis. Jpn J Infect Dis 64: 272-276.

219. Diaz R, Casanova A, Ariza J, Moriyon I (2011) The Rose Bengal test in human brucellosis: a neglected test for the diagnosis of a neglected disease. PLoS Negl Trop Dis 5: e 950

220. Ruiz-Mesa JD, Sánchez-Gonzalez J, Reguera JM, Martín L, Lopez-Palmero S, et al. (2005) Rose Bengal test: diagnostic yield and use for the rapid diagnosis of human brucellosis in emergency departments in endemic areas. Clin Microbiol Infect 11: 221-225

221. Mantur B, Parande A, Amarnath S, Patil G, Walvekar R, et al. (2010) ELISA versus conventional methods of diagnosing endemic brucellosis. Am J Tropical Med Hyg 83: 314-318

222. Agasthya AS, Isloor S, Krishnamsetty P (2012) Seroprevalence study of human brucellosis by conventional tests and indigenous indirect enzymelinked immunosorbent assay. ScientificWorldJournal 2012:104239.

223. Sippel JE, El-Masry AA, Farid Z (1982) Diagnosis of human brucellosis with ELISA. Lancet 320: 19-21.

224. Park SH, Lee YH, Chu H, Hwang SD, Hwang KJ, et al. (2012) Application of the microagglutination test for serologic diagnosis of human brucellosis. Osong Public Health Res Perspect 3: 19-23.

225. Sarguzel FM, Kayman T, Celik I, Koc N (2011) Comparison of standard tube agglutination, Coombs' and BrucellaCapt tests in the diagnosis of brucellosis. New J Med 28:113-115.

226. Taleski V (2010) An overview of introducing various laboratory tests for diagnosis of human brucellosis in the republic of Macedonia. Macedoninan J Med Sci 3: 239-245

227. Nielsen K, Gall D (2001) Fluorescence polarization assay for the diagnosis of brucellosis: a review. J Immunoassay Immunochem 22:183-201.

228. Casao MA, Navarro E, Solera J (2004) Evaluation of BrucellaCapt for the diagnosis of human brucellosis. J Infect 49: 102-108.

229. Sayan M, Erdenlig S, Stack S, Kilic S, Guducuoglu H, et al. (2011) A serological diagnostic survey for Brucella canis infection in Turkish patients with brucellosis-like symptoms. Jpn J Infect Dis 64: 516-519.

230. Lucero NE, Escobar GI, Ayala SM, Jacob N (2005) Diagnosis of human brucellosis caused by Brucella canis. J Med Microbiol 54: 457-461.

231. Ahmadinejad Z, Abdollahi A, Ziaee V, Domiraei Z, Najafizadeh SR, et al (2016) Prevalence of positive autoimmune biomarkers in the brucellosis patients. Clin Rheumatol. Epub ahead of print.
232. Refik M, Mehmet N, Durmaz R, Ersoy Y (2004) Cytokine profile and nitric oxide levels in sera from patients with brucellosis. Braz J Med Biol Res 37: 1659-1663.

233. Benz F, Roy S, Trautwein C, Roderburg C, Luedde T (2016) Circulating MicroRNAs as Biomarkers for Sepsis. Int J Mol Sci 17: pii: E78.

234. Wang H, Yin F, Shen DX, Zhang YJ, Luo YP, et al. (2013) Predictive value of procalcitonin for excluding bloodstream infection: results of a retrospective study and utility of a rapid, quantitative test for procalcitonin. J Int Med Res 41: 1671-1681.

235. Wang Y, Wang Z, Zhang Y, Bai L, Zhao Y, et al. (2014) Polymerase chain reaction-based assays for the diagnosis of human brucellosis. Ann Clin Microbiol Antimicrob 13.

236. Yu WL, Nielsen K (2010) Review of detection of Brucella spp. by polymerase chain reaction. Croatian Med J 51: 306-313

237. Navarro E, Casao MA, Solera J (2004) Diagnosis of human brucellosis using PCR. Expert Rev Mol Diagn 4:115-123.

238. Gemechu MY, Gill JP, Arora AK, Ghatak S, Singh DK (2011) Polymerase chain reaction (PCR) assay for rapid diagnosis and its role in prevention of human brucellosis in Punjab, India. Int J Prev Med 2: 170-177.

239. Al-Attas RA, Al-Khalifah M, Al-Qurashi AR, Badawy M, Al-Gualy N (2000) Evaluation of PCR, culture and serology for the diagnosis of acute human brucellosis. Ann Saudi Med 20: 224-228.

240. Sue MJ, Yeap SK, Omar AR, Tan SW (2014) Application of PCR-ELISA in molecular diagnosis. Biomed Res Int 2014: 653014.

241. Vrioni G, Gartzonika C, Kotsoula A, Boboyianni C, Papadopoulou C, et al (2004) Application of a polymerase chain reaction enzyme immunoassay in peripheral whole blood and serum specimens for diagnosis of acute human brucellosis. Eur J Clin Microbiol Infect Dis 23: 194-199.

242. Wang Y, Ke Y, Zhen Q, Yuan X, Xu J, et al. (2012) Complete genome sequence of Brucella canis BCB018, a strain isolated from a human patient. J Bacteriol 194: 6697-6698.

243. Tevdoradze E, Farlow J, Kotorashvili A, Skhirtladze N, Antadze I, et al. (2015) Whole genome sequence comparison of ten diagnostic Brucellaphages propagated on two Brucella abortus hosts. Virol J 12: 66 .

244. Her M, Kang SI, Kim JW, Kim JY, Hwang IY, et al. (2010) A genetic comparison of Brucella abortus isolates from animals and humans by using the /mlva assay. J Microbiol Biotechnol 20: 1750-1755

245. Menshawy AM, Perez-Sancho M, Garcia-Seco T, Hosein HI, García N, et al. (2014) Assessment of genetic diversity of zoonotic Brucella spp. recovered from livestock in Egypt using multiple locus VNTR analysis. Biomed Res Int 2014: 353876

246. Pathak AD, Dubal ZB, Doijad S, Raorane A, Rodrigues S, et al. (2014) Human brucellosis among pyrexia of unknown origin cases and occupationally exposed individuals in Goa Region, India. Emerg Health Threats J 7: 23846.

247. Mir T, Nabi Dhobi G, Nabi Koul A, Saleh T (2014) Clinical profile of classica Fever of unknown origin (FUO). Caspian J Intern Med 5: 35-39.

248. Ergül N, Cermik TF (2011) FDG-PET or PET/CT in fever of unknown origin the diagnostic role of underlying primary disease. Int J Mol Imaging 2011: 318051.

249. Mete B, Vanli E, Yemisen M, Balkan II, Dagtekin H, et al. (2012) The role of invasive and non-invasive procedures in diagnosing fever of unknown origin. Int J Med Sci 9: 682-689.

250. Ioannou S, Chatziioannou S, Pneumaticos SG, Zormpala A, Sipsas NV (2013) Fluorine-18 fluoro-2-deoxy-D-glucose positron emission tomography/ computed tomography scan contributes to the diagnosis and management of Brucella spondylodyskitis. BMC Infect Dis 13: 73.

251. Zhang T, Wang C, Niu R, Wang X (2014) Pulmonary brucellosis on PET/CT Clin Nucl Med 39: 222-223. 
252. Alavi SM, Alavi L (2013) Treatment of brucellosis: a systematic review of studies in recent twenty years. Caspian J Intern Med 4: 636-641.

253. Yousefi-Nooraie R, Mortaz-Hejri S, Mehrani M, Sadeghipour P (2012) Antibiotics for treating human brucellosis. Cochrane Database. Syst Rev 10 CD007179.

254. Solís García del Pozo J, Solera J (2012) Systemic review and meta-analysis of randomized clinical trials in the treatment of human brucellosis. PLoS One 7: e32090.

255. Skalsky K, Yahav D, Bishara J, Pitlik S, Leibovici L, Paul M (2008) Treatment of human brucellosis: systematic review and meta-analysis of randomized controlled trials. Br Med J 336: 701-704.

256. Solera J, Martínez-Alfaro E, Sáez L (1994) Meta-analysis of the efficacy of the combination of + rifampicin and doxycycline in the treatment of human brucellosis. Med Clin (Barc) 102: 731-738.

257. Bayram Y, Korkoca H, Aypak C, Parlak M, Cikman A, et al. (2011) Antimicrobial susceptibilities of Brucella isolates from various clinical specimens. Int J Med Sci 8: 198-202.

258. Al Johani S (2014) In virto activities of tigecycline against Brucella spp. in an endemic area. Afr J Microbiol Res 8: 1837-1840.

259.Pandit DP, Pandit PT (2013) Human brucellosis: are we neglecting an enemy at the backyard? Med J DY Patil Univ 6: 350-358.

260. Karaagac L, Koruk ST, Koruk I, Aksoy N (2011) Decreasing oxidative stress in response to treatment in patients with brucellosis: could it be used to monitor treatment? Int J Infect Dis 15: e346-e349.

261. Kinsara A, Al-Mowallad A, Osoba AO (1999) Increasing resistance of Brucellae to co-trimoxazole. Antimicrob Agents Chemother 43: 1531.
262. Neto AM, Corção G, Dasso MG, Keid LB, de Costa M (2014) Antimicrobial susceptibility profile of Brucella spp. isolated in Brazil. Rev Patol Trop 43: 163-172.

263. Ayaşlioğlu E, Kiliç S, Aydin K, Kiliç D, Kaygusuz S, Ağalar C (2008) Antimicrobial susceptibility of Brucella melitensis isolated from blood samples. Turkish J Med Sci 38: 257-262.

264. Tanyel E, Coban AY, Koruk ST, Simsek H, Hepsert S, et al. (2007) Actual antibiotic resistance pattern of Brucella melitensis in central Anatolia. An update from an endemic area. Saudi Med J 28: 1239-1242.

265. Hashim R, Ahmad N, Mohamed Zahidi J, Tay BY, Mohd Noor A, et al. (2014) Identification and invitro antimicrobial susceptibility of Brucella species isolated from human brucellosis. Int J Microbiol. 2014:596245.

266. Trujillano-Martín I, García-Sánchez E, Martínez IM, Fresnadillo MJ, GarcíaSánchez JE, et al. (1999) In vitro activities of six new flouroquinolones against Brucella melitensis. Antimicrob Agents Chemother 43: 194-195

267. Marianelli G, Ciuchini F, Tarantino M, Pasquali P, Adone R (2004) Genetic basis of the rifampicin resistance phenotype in Brucella spp. J Clin Microbiol 42: 5439-5443.

268. Donev D (2010) Brucellosis Control and Eradication in the South Eastern European Countries: Current Status and Perspective Strategies. Macedonian J Med Sci 3: 220-228.

269. Refai M (2002) Incidence and control of brucellosis in the Near East region. Vet Microbiol 90: 81-100.

270. Hotez PJ, Savioli L, Fenwick A (2014) Neglected tropical diseases of the Middle East and North Africa: review of their prevalence, distribution and opportunities for control. PLoS Negl Trop Dis 6: e 1475.

Copyright: (C) 2016 Al-Anazi KA, et al. This is an open-access article distributed under the terms of the Creative Commons Attribution License, which permits unrestricted use, distribution, and reproduction in any medium, provided the original author and source are credited. 